University of Zurich

Department of Economics

Working Paper Series

ISSN 1664-7041 (print)

ISSN 1664-705X (online)

Working Paper No. 351

\title{
Negative Interest Rates, Capital Flows and Exchange Rates
}

Romina Ruprecht

June 2020 


\title{
Negative Interest Rates, Capital Flows and Exchange Rates *
}

\author{
Romina Ruprecht \\ University of Basel
}

June 29, 2020

\begin{abstract}
This paper develops a dynamic general equilibrium model with two currencies to study the effect of negative interest rates on domestic money demand and exchange rates. Money demand for a currency depends on the relative ratio of the money market rate and the deposit rate of the central bank. If agents choose to hold only domestic currency, a decrease in the deposit rate of the central bank will not affect the exchange rate. If agents choose to hold both currencies, a decrease in the deposit rate will cause an appreciation (depreciation) if the money market rate decreases to a larger (smaller) extent. If agents are subject to bank deposit rates that are sticky below zero, then a decrease of the central bank deposit rate leads to a depreciation of the currency regardless of the size of the effect on the money market rate.

Keywords: monetary policy, negative interest rates, exchange rates

JEL Classifications: E52, E58, F31
\end{abstract}

${ }^{*}$ I am grateful to my advisors Aleksander Berentsen and Francesca Carapella and my collegues Mohammed Aït Lahcen, Lukas Altermatt and Florian Madison for valuable feedback that greatly improved the paper. I thank Gabriele Camera, Pedro Gomis-Porqueras, Sarah Lein, Fernando Martin, Cyril Monnet, B. Ravikumar, Rolf Weder, Randy Wright and the participants of the Gerzensee Alumni Conference 2017, the participants of the Models in Money and Banking workshop at the University of Bern in 2018, participants of the Economics Lunch at the University of Basel in Spring 2018 and the participants of the Seminar in Monetary Theory in Marrakech 2018 and 2019 for helpful comments. 


\section{Introduction}

In recent years, several central banks adopted negative interest rates (NIR) as a monetary policy tool for various reasons. The Danmarks Nationalbank and the Swiss National Bank (SNB) have introduced NIR for exchange rate considerations while the Bank of Japan, the Swedish Riksbank and the European Central Bank have implemented NIR to increase inflation. In Switzerland, the Swiss franc experienced a high appreciation relative to the euro, which lead the SNB to introduce an exchange rate peg in 2011. This peg was defended until the beginning of 2015, when the SNB decided to discontinue the peg, lower the key policy rate to $-0.75 \%$ and charge $-0.75 \%$ on any excess reserves above a certain threshold. ${ }^{1}$ The SNB decided to adopt NIR to make investments in Switzerland relatively less attractive and thus hinder a further appreciation of the Swiss franc.

In order to study the effects of NIR on money demand, capital flows and exchange rates, I develop a small open economy model with two currencies. In the model, financial intermediaries (FI) are subject to uncertainty about their liquidity needs and can adjust their portfolio in either a domestic or foreign money market once their liquidity needs are revealed. Accessing the foreign money market entails additional transaction costs. Sellers of the consumption good accept both domestic and foreign currencies but are subject to the interest rate on overnight reserves set by the central banks.

The key result of the model is that the demand for domestic or foreign currency crucially depends on the ratio of the money market rate and the deposit rate of the central bank, relative to the same ratio in the foreign currency. FI prefer to acquire the currency in which the marginal cost of borrowing is relatively small compared to the marginal benefit of holding a currency across periods. Depending on this ratio of the domestic and the foreign currency, the effects of a decrease in the NIR on exchange rates differ.

If the ratio of the money market rate and the deposit rate is higher in the domestic currency than it is in the foreign currency, domestic FI choose to use the domestic currency only. ${ }^{2}$ In such an equilibrium, a decrease in the interest rate on reserves of the central bank does not affect the exchange rate because it does not change money demand for the domestic currency.

If however, the ratio of the money market rate and the deposit rate of the central bank is smaller for the domestic than it is for the foreign currency, the central bank can affect the exchange rate through the deposit rate. FI with a high liquidity preference will choose to acquire the foreign currency, allowing them to consume a higher quantity. In such a scenario, the effect of a decrease in the deposit rate on exchange rates depends on

\footnotetext{
${ }^{1}$ In December 2015 , the SNB announced a decrease in the policy rate to $-0.25 \%$ effective by January $21^{\text {st }} 2015$. On January $15^{\text {th }}$, the SNB announced a further decrease to $-0.75 \%$, also effective as of January $21^{\text {st }} 2015$.

${ }^{2}$ In the model, I focus on the money demand of domestic agents. Foreign currency is demanded by foreign agents and therefore valued in equilibrium.
} 
the difference between the ratios of the two currencies. Namely, if there is only a small difference between the two currencies, a decrease in the deposit rate decreases the incentive to hold the domestic currency and the ratio between the money market rate and the deposit rate in the domestic currency decreases. As a result, FI will choose to acquire less of the domestic currency and more FI choose to acquire the foreign currency. Thus, the domestic currency depreciates and the capital outflow of domestic FI increases.

On the other hand, if there is a large difference between the two currencies, a decrease in the deposit rate leads to an increase in the ratio of the money market rate and the deposit rate of the domestic currency. As a result, the domestic currency becomes more attractive to hold and it appreciates. Moreover, less FI choose to acquire the foreign currency and as a result, capital outflow decreases.

These results do not depend on the sign of the deposit rate, indicating that the effects to not differ between positive rates and NIR. However, several papers in the NIR literature argue that banks do not pass on the NIR to their depositors (see, for example Heider et al. (2019), Demiralp et al. (2019), Dell'Ariccia et al. (2017) and others), suggesting that NIR may have different effects on the economy.

Thus, I extend this benchmark model to account for these observations and assume that sellers deposit their earnings at bank accounts with FI, which are remunerated at a retail bank deposit rate which is subject to a zero lower bound. The key result of the extension is that the ratio of the marginal cost of borrowing and the marginal benefit of holding a currency across periods no longer depends on the central bank deposit rate but rather on the retail bank deposit rate. Thus, a decrease in the central bank deposit rate only affects the exchange rate in a floor system where the money market rate moves with the central bank deposit rate. Here, a decrease in the central bank deposit rate leads to an appreciation of the currency because the cost of borrowing decreases relative to the benefit of holding a currency across periods.

The extension suggests that NIR may have counter-intuitive effects on exchange rates due to a limited pass-through to retail bank deposit rates. However, recent observations show that banks pass on NIR to firms and wealthy customers with the prolonged exposure of NIR, indicating that the results in the benchmark model may still have some relevance in NIR periods.

This paper is closely related to Amador et al. (2017), Khayat (2018), Hameed and Rose (2018), who study the effects of NIR on exchange rates or discuss NIR as a monetary policy tool to replace foreign reserve accumulation. This paper contributes to the discussion on the effects of NIR on exchange rates by developing a small open economy model to study how NIR affects money demand, capital flows and exchange rates.

This paper is structured as follows. Section 2 provides an overview of the related literature. In section 3, I describe the theoretical model. Section 4 discusses the results of 
the benchmark model and the results of the extension. Section 5 concludes.

\section{Related literature}

This paper is closely related to the literature that studies monetary policy and their effects on exchange rates. While there exists a large literature that studies the effects of monetary policy and exchange rates (see, for example Mishkin, 1995, Taylor, 2001, Obstfeld and Rogoff, 1995 or Eichenbaum and Evans, 1995), there are only a few papers that discuss NIR and their effects on the exchange rate. Hameed and Rose (2018) analyse the effects of NIR on exchange rate volatility using Swiss data. They find only little evidence that NIR affect exchange rate volatility. Khayat (2018) estimates Markov regime switching with time varying transition probabilities models to investigate the relationship of NIR on exchange rates and banking outflows and finds stronger effects during a NIR period compared to a positive interest rate period in Denmark. Amador et al. (2017) discus NIR as a monetary policy tool to target exchange rates. They study the benefits and costs arising from targeting an exchange rate by acquiring foreign reserves and present NIR as a tool to avoid some of these costs.

Other papers on the effects of NIR include Bech and Malkhozov (2016), Jackson (2015), Turk (2016), Jobst and Lin (2016) and Dell'Ariccia et al. (2017), who provide an overview of NIR policies, and discuss transmission to money markets and potential side effects. The theoretical literature on NIR focuses on optimal monetary policy under NIR (Rognlie, 2016, Dong and Wen, 2017, Porcellacchia, 2018), on the effects on bank lending (Eggertsson et al., 2019) or on the impact on banks (Berentsen and Ruprecht, 2020). The empirical literature focuses mostly on the impact on banks' balance sheets, bank lending and lending rates (Heider et al., 2019, Basten and Mariathasan, 2018, Bräuning and Wu, 2017, Demiralp et al., 2019, Eisenschmidt and Smets, 2019, Eggertsson et al., 2019, Turk, 2016, Schelling and Towbin, 2018).

This paper is furthermore closely related to the extensive literature that studies monetary policy in a channel or floor system and its transmission to money markets. Articles include Poole (1968), Woodford (2000), Heller and Lengwiler (2003), Whitesell (2006), Berentsen and Monnet (2008), Berentsen et al. (2014) or Bech and Monnet (2016). These papers however do not study NIR.

The paper is also related to the literature on the indeterminacy of exchange rates in theoretical models, first discussed in Kareken and Wallace (1981), and how to overcome it (see, for example, Liu, 2016, Nosal and Rocheteau, 2011, Camera et al., 2004, GomisPorqueras et al., 2013, Gomis-Porqueras et al., 2017, Zhang, 2014 or Lucas, 1982). 


\section{The model}

\subsection{The environment}

The theoretical model builds on Berentsen et al. (2014) and Berentsen et al. (2018), who develop a framework that closely replicates how monetary policy is implemented in reality. To incorporate two currencies, I follow the approach taken in Zhang (2014), where using the foreign currency is subject to a cost.

Time is discrete and continues forever. Agents discount future periods with $\beta=1 /(1+$ $r)<1$, where $r$ is the time rate of discount. There are two countries, indexed by 1 and 2. For now, I focus on the environment in country 1, to which I also refer as the domestic country. Each period is divided into three sub-periods that open sequentially, as depicted in Figure 1. These are a settlement and foreign exchange market, a money market and a goods market. There are two types of infinitely-lived agents: FI and sellers, each with a unit measure. FI want to consume in the goods market, but cannot produce and sellers can produce in the goods market, but do not want to consume. There exist further a central bank in each country, that issue their own currency, currency 1 and currency 2, respectively and operate standing facilities.

Money and limited commitment. Goods are non-storable and agents cannot commit to honour intertemporal promises to repay. In order to trade, agents can use currency 1 or currency 2 as a medium of exchange.

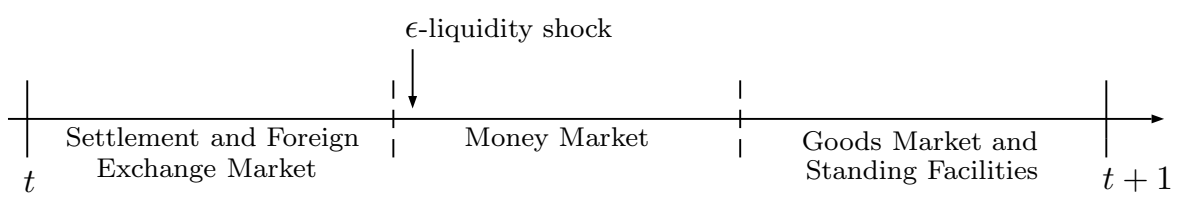

Figure 1: Timeline

I now describe the three sub-periods.

Money market. Agents enter the money market with $m^{1}$ money holdings of currency 1. At the beginning of the money market, FI receive an i.i.d. idiosyncratic and serially uncorrelated liquidity preference shock denoted $\varepsilon$ with distribution $F(\varepsilon)$ and support $(0, \infty]$. In order to adjust their money holdings according to their liquidity preferences, FI can access a perfectly competitive money market in country 1 or/and in country 2 to borrow or lend currency 1 or 2 , respectively. ${ }^{3}$ In each money market only the respective currency

\footnotetext{
${ }^{3}$ There are several studies that examine money markets closely, see for example Berentsen et al. (2018) for Switzerland and European Central Bank (2015) or Mancini et al. (2016) for the Euro area. These studies suggest that market for reserves in Switzerland, the Swiss Franc Repo Market and the collateralized money market in the Euro zone are competitive markets.
} 
is traded. The price of one unit borrowed is $1 / \rho_{m}^{j}$ with $\rho_{m}^{j}=1 /\left(1+i_{m}^{j}\right)$, where $i_{m}^{j}$ is the nominal interest rate in money market $j$, for $j=1,2$. I abstract from default in the money market by assuming that there exists a record-keeping technology such that the repayment of credit can enforced. This record-keeping technology does not exist in the goods market. Thus, FI can borrow on an uncollateralized basis.

Goods market and standing facilities. In the competitive goods market, sellers produce a specialized good $q_{s}$ at linear cost $c\left(q_{s}\right)=q_{s}$. FI purchase the good and receive utility $\varepsilon u\left(q_{\varepsilon}\right)=\varepsilon \log \left(q_{\varepsilon}\right){ }^{4}{ }^{4}$ Sellers accept both currencies and have no costs associated with accepting a foreign currency. Furthermore, the central banks operate a lending and a deposit facility. Thus, agents can borrow from the central bank at price $1 / \rho_{\ell}^{j}=\left(1+i_{\ell}^{j}\right)$, where $i_{\ell}^{j}$ is the lending rate for $j=1,2$ and deposit money holdings at the central bank at price $1 / \rho_{d}^{j}=\left(1+i_{d}^{j}\right)$, where $i_{d}^{j}$ is the deposit rate for $j=1,2$. The central bank of each country only lends and accepts deposits in it's own currency. Sellers can only carry their earnings across periods by depositing them at the central bank. ${ }^{5}$

Settlement and foreign exchange market. In the settlement and foreign exchange market, FI repay their loans from the money market and from the central banks. Both FI and sellers can consume a general good $x$, which yields linear utility $U(x)=x$. They can furthermore work $h$ hours, yielding a linear disutility $-h$. One hour of work yields one general good. Furthermore, FI decide how much currency 1, denoted $m^{1^{\prime}}$ to bring into the next money market. The assumption of quasi-linear preferences follows Lagos and Wright (2005) and as shown below yields a degenerate distribution of currency 1 holdings. The price of the general good is $P^{j}=1 / \phi^{j}$ for $j=1,2$. Thus, $\phi^{j}$ denotes the price of one unit of currency $j$ for $j=1,2$ in terms of the general good. Sellers and FI can exchange their currency holdings by either purchasing the general good with one currency and selling it for the other or directly exchange currencies with agents that hold the required currency. Lastly, the central banks issue currencies 1 and 2 in the settlement and foreign exchange market. The total stock of currency 1 and 2 in period $t$ is denoted $M^{1}$ and $M^{2}$, respectively.

Two-country environment. In country 2, there are also two types of agents: FI and sellers. Each of them has measure $n$, where $n$ is assumed to be large relative to country 1 such that any decisions taken by agents in country 1 do not affect the equilibrium outcome in country 2 .

\footnotetext{
${ }^{4}$ Another way to model the goods market would be to have buyers that deposit their money holdings at accounts held with FI because they are subject to uncertainty about their consumption preferences. Buyers can then withdraw the required amount of deposits in the goods market and if necessary borrow from FI. FI adjust their money holdings in the money market to meet the withdrawals of buyers. Here, I assume that buyers and FI are consolidated.

${ }^{5}$ Here, I abstract from cash holdings. This assumption is motivated by the implementation of NIR in Switzerland. The Swiss National Bank monitors cash holdings of banks and charges NIR on cash holdings, if cash balances increase. Thus, cash cannot be used to avoid NIR.
} 


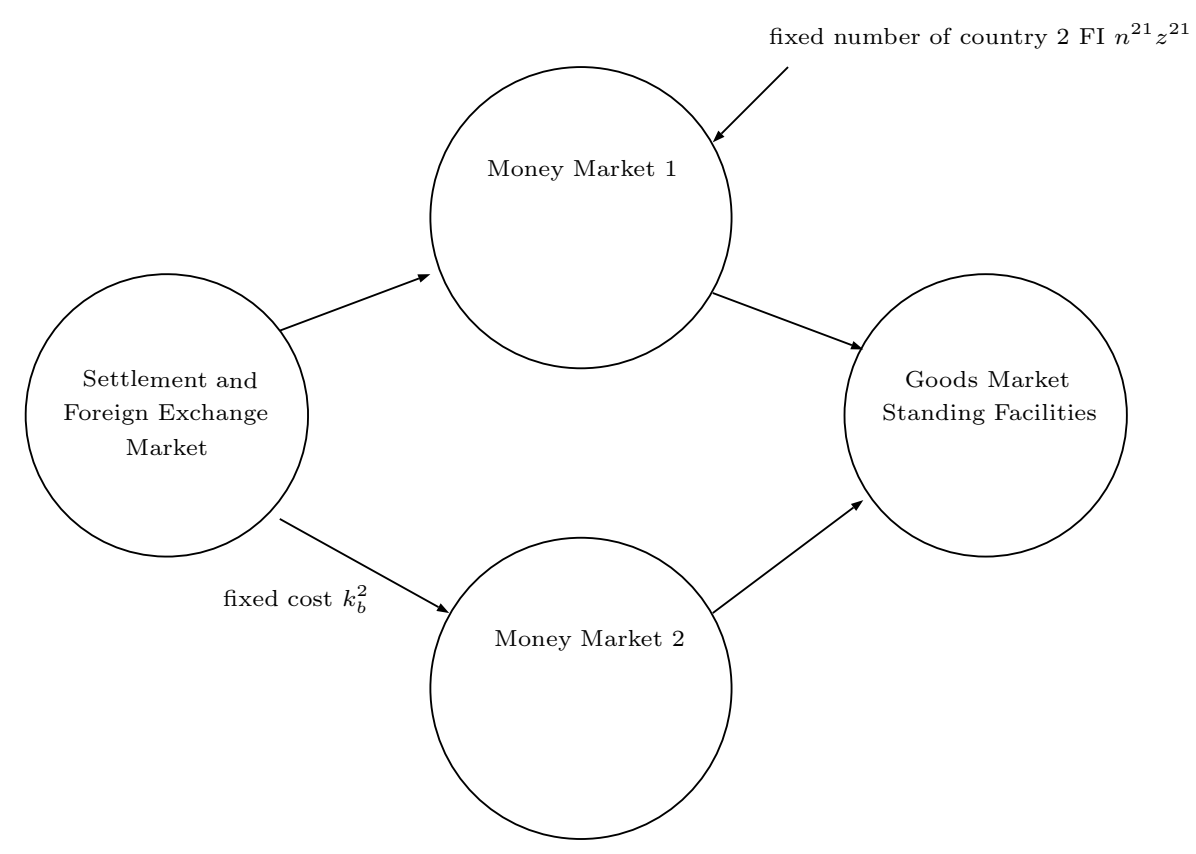

Figure 2: Two country environment

Figure 2 gives an overview of the environment. At the beginning of the period, both agents of country 1 and agents of country 2 can trade with each other in the settlement and foreign exchange market. As described above they can readjust their portfolios by working and consuming the general good and exchanging currencies at the exchange rate $e$, which is determined by the ratio of the respective price levels in the settlement and foreign exchange market:

$$
e=\frac{P^{1}}{P^{2}}=\frac{\phi^{2}}{\phi^{1}}
$$

Note, since country 2 is assumed to be large and cannot be affected by any decisions taken by country 1 agents, $\phi^{2}$ is exogenous. After the settlement and foreign exchange market, country $1 \mathrm{FI}$ can then choose to access money market 1 and/or money market 2 . Accessing money market 2 is subject to a fixed cost $k_{b}^{2}$ for country 1 FI. Furthermore, in order to focus on the effects of NIR on domestic money demand, I assume that the number of country $2 \mathrm{FI}$ that enter money market 1 and how much they borrow is fixed at $n^{21} z^{21}$. Lastly, FI and sellers enter the goods market. Here, I assume that the goods market is perfectly divided between the two countries, i.e. country 1 FI only purchase from country 1 sellers and country 2 FI only purchase from country 2 sellers. After the trade, sellers deposit their earnings with the respective central bank. For the following analysis, I focus on the maximization problems of country 1 agents only and take the behaviour of country 
2 agents as exogenous. ${ }^{6}$

Assumption 1. Agents can only hold their domestic currency at the end of the settlement and foreign exchange market.

Assumption 1 pins down the money demand in the settlement and foreign exchange market and ensures that currency 1 is always valued in a monetary equilibrium. Further, it implies that FI from country 1 that would like to lend out money in the money market, can only access the money market in country 1 , since each money market only trades in their respective currency. A country 1 FI that would like to borrow can choose whether to borrow currency 1 in money market 1 or currency 2 in money market 2 .

\subsection{First-best allocation}

The first-best allocation is characterized by a benevolent planner who can implement an allocation to maximize the utility of all agents in the economy. The benevolent planner weighs the utilities of all agents equally.

$$
\begin{gathered}
\max _{q_{\varepsilon}, q_{s}} \int_{0}^{\infty}\left(\varepsilon u\left(q_{\varepsilon}\right)-q_{s}\right) d F(\varepsilon) \\
\text { s.t. } q_{s}-\int_{0}^{\infty} q_{\varepsilon} d F(\varepsilon) \geq 0
\end{gathered}
$$

The first-order condition and market clearing in the goods market imply

$$
\begin{aligned}
& q_{\varepsilon}^{*}=\varepsilon \forall \varepsilon \\
& q_{s}=\bar{\varepsilon}, \text { where } \bar{\varepsilon}=\int_{0}^{\infty} \varepsilon d F(\varepsilon) .
\end{aligned}
$$

In the first-best allocation, FI consume a quantity of the consumption good that is equal to their $\varepsilon$ and each seller produces the average of the total amount demanded.

\subsection{Decentralized allocation}

Here, I characterize the optimal decisions of FI and sellers. I focus on the decisions of FI as sellers play a secondary role in the model. I use them to obtain a first-order condition in the goods market.

\footnotetext{
${ }^{6}$ A study by Yeşin (2015) shows that the high valuation of the Swiss franc was not caused by a high private capital inflow, suggesting that the appreciation of the Swiss franc was at least to some extent caused by private capital flows of domestic agents. For this reason, I focus on the demand for domestic and foreign currency by domestic agents.
} 
Settlement and Foreign Exchange Market. $\quad V_{S}\left(m^{1}, m^{2}, \ell^{1}, \ell^{2}, d^{1}, d^{2}, z^{1}, z^{2}\right)$ denotes the value of a FI when entering the settlement and foreign exchange market with $m^{1}$ currency 1 holdings, $m^{2}$ currency 2 holdings, $\ell^{1}$ loans from country 1's central bank, $\ell^{2}$ loans from country 2's central bank, $d^{1}$ deposits at country 1's central bank, $d^{2}$ deposits at country 2's central bank, $z^{1}$ loans from country 1's money market and $z^{2}$ loans from country 2's money market. $V_{M}\left(m^{1^{\prime}}\right)$ denotes the expected value of entering the money market with $m^{1^{\prime}}$ currency 1 holdings. For notational simplicity, I omit the time subscript of the value function. The value function at the beginning of the settlement and foreign exchange market is

$$
\begin{gathered}
V_{S}\left(m^{1}, m^{2}, \ell^{1}, \ell^{2}, d^{1}, d^{2}, z^{1}, z^{2}\right)=\max _{h, x, m^{1^{\prime}}} x-h+V_{M}\left(m^{1^{\prime}}\right) \\
\text { s.t. } x+\phi^{1} m^{1^{\prime}}=h+\phi^{1} m^{1}+\phi^{2} m^{2}+\phi^{1} \frac{d^{1}}{\rho_{d}^{1}}+\phi^{2} \frac{d^{2}}{\rho_{d}^{2}}-\phi^{1} \frac{\ell^{1}}{\rho_{\ell}^{1}}-\phi^{2} \frac{\ell^{2}}{\rho_{\ell}^{2}}-\phi^{1} \frac{z^{1}}{\rho_{m}^{1}}-\phi^{2} \frac{z^{2}}{\rho_{m}^{2}}+\phi^{1} \tau M^{1},
\end{gathered}
$$

where $h$ is the number of hours worked, $x$ the quantity of the general good consumed and $m^{1^{\prime}}$ is the amount of currency 1 brought into the money market. $\phi^{j} d^{j} / \rho_{d}^{j}$ is the amount of deposits FI receive back from central bank $j$, for $j=1,2$. $\phi^{j} \ell^{j} / \rho_{\ell}^{j}$ is the amount FI have to pay back to central bank $j$ for $j=1,2$ and $\phi^{j} z^{j} / \rho_{m}^{j}$ is the amount FI have to pay back from borrowing $z^{j}$ in money market $j$, for $j=1,2$. Lastly, $\phi^{1} \tau M^{1}$ are lump-sum taxes $(\tau<0)$ or lump-sum subsidies $(\tau>0)$ from the central bank. Rearranging the budget constraint for $x-h$ and plugging the expression into the value function, I obtain the following first-order condition

$$
V_{M}^{m^{1^{\prime}}} \leq \phi^{1}\left(=\text { if } m^{1^{\prime}}>0\right) .
$$

The marginal value of bringing one additional unit of currency 1 into the money market is $V_{M}^{m^{1^{\prime}}}=\frac{\partial V_{M}\left(m^{1^{\prime}}\right)}{\partial m^{1^{\prime}}}$. Since agents have linear disutility of working, $\phi^{1}$ is the marginal cost of acquiring one unit of currency 1 in the settlement and foreign exchange market. Equation (4) implies that all FI enter the money market with the same amount of $m^{1^{\prime}}$ currency holdings, regardless of their currency balances when entering the settlement and foreign exchange market. This yields a degenerate distribution of currency 1 holdings. The envelope conditions are

$$
V_{S}^{m^{1}}=\phi^{1}, V_{S}^{m^{2}}=\phi^{2}, V_{S}^{\ell^{j}}=-\frac{\phi^{j}}{\rho_{\ell}^{j}}, V_{S}^{d^{j}}=\frac{\phi^{j}}{\rho_{d}^{j}}, V_{S}^{z^{j}}=-\frac{\phi^{j}}{\rho_{m}^{j}},
$$

for $j=1,2 . V_{S}^{h^{j}}$ is the partial derivative of $V_{S}\left(m^{1}, m^{2}, \ell^{1}, \ell^{2}, d^{1}, d^{2}, z^{1}, z^{2}\right)$ with respect to $h^{j}$, where $h=m, \ell, d, z$ for $j=1,2$. 
Money and Goods Market. If

$$
\frac{\phi^{1}}{\beta \phi_{+1}^{1}} \geq \frac{1}{\rho_{m}^{1}}
$$

holds, sellers choose not to carry any money into the money and goods market. $\phi_{+1}^{j}$ denotes the value of currency $j$ for $j=1,2$ in the settlement and foreign exchange market in the following period. For the remainder of this paper, I assume that this condition is satisfied. Further, since sellers have no need to acquire a means of payment, they also have no incentive to borrow in the money market or at the central bank. Therefore $z^{j}=\ell^{j}=0$ for $j=1,2$ for sellers.

Denote $V_{G}^{S}$ the value function of a seller at the beginning of the goods market. Sellers choose how much to produce and sell in return for receiving currency 1 , denoted $q_{s}^{11}$, at price $p^{11}$ and how much to produce and sell for currency 2, denoted $q_{s}^{12}$, at price $p^{12}$. Their maximization problem is therefore

$$
\begin{gathered}
V_{G}^{S}=\max _{q_{s}^{11}, q_{s}^{12}}-q_{s}^{11}-q_{s}^{12}+\beta V_{S}^{1}\left(m^{1}+p^{11} q_{s}^{11}-d^{1}, \frac{p^{12}}{e_{+1}} q_{s}^{1}-d^{2}, 0,0, d^{1}, d^{2}, 0,0\right) \\
\text { s.t. } m^{1}+p^{11} q_{s}^{1}-d^{1} \geq 0, \frac{p^{12}}{e_{+1}} q_{s}^{1}-d^{2} \geq 0
\end{gathered}
$$

The first and second constraint state that the deposits of sellers at the respective central bank cannot exceed their currency holdings. Since, I assume that sellers deposit all their earnings at the central bank, these constraints hold with equality. Sellers are indifferent as to which currency to accept and how much to produce if

$$
\beta \phi_{+1}^{1} \frac{p^{11}}{\rho_{d}^{1}}=\beta \phi_{+1}^{1} \frac{p^{12}}{\rho_{d}^{2}}=1
$$

holds. Equation (6) implies that sellers need to be compensated for the cost of carrying currency 1 or currency 2 across periods.

FI receive their liquidity preference shock at the beginning of the money market and decide based on this shock how much to borrow or lend in the money market, which money market to access and how much to consume in the goods market. Denote $V_{G}\left(m^{1}\right)$ the value function of a FI at the beginning of the money market with $m^{1}$ currency 1 holdings. Let $q_{\varepsilon}^{11}$ denote the amount purchased in currency 1 and $q_{\varepsilon}^{12}$ denote the amount purchased with currency 2 , where $q_{\varepsilon}=q_{\varepsilon}^{11}+q_{\varepsilon}^{12}$. Denote $V_{M}^{11}\left(m^{1}\right)$ the value of an $\varepsilon$-FI that accessed money market 1 . The maximization problem of an $\varepsilon$-FI that chose to access market 1 is 


$$
\begin{aligned}
& V_{M}^{11}\left(m^{1}\right)=\max _{q_{\varepsilon}^{11}, z_{\varepsilon}^{1}, \ell_{\varepsilon}^{1}, \ell_{\varepsilon}^{2}, d_{\varepsilon}^{1}, d_{\varepsilon}^{2}} \varepsilon u\left(q_{\varepsilon}\right) \\
& +\beta V_{S}\left(m^{1}+z_{\varepsilon}^{1}+\ell_{\varepsilon}^{1}-p^{11} q_{\varepsilon}^{11}-d_{\varepsilon}^{1}, \ell_{\varepsilon}^{2}-\frac{p^{12}}{e_{+1}} q_{\varepsilon}^{12}-k_{b}^{2}-d_{\varepsilon}^{2}, \ell_{\varepsilon}^{1}, \ell_{\varepsilon}^{2}, d_{\varepsilon}^{1}, d_{\varepsilon}^{2}, z_{\varepsilon}^{1}, z_{\varepsilon}^{2}\right) \\
& \text { s.t. } m^{1}+z_{\varepsilon}^{1}+\ell_{\varepsilon}^{1}-p^{11} q_{\varepsilon}^{11}-d_{\varepsilon}^{1} \geq 0, \quad \ell_{\varepsilon}^{2}-\frac{p^{12}}{e_{+1}} q_{\varepsilon}^{12}-k_{b}^{2}-d_{\varepsilon}^{2} \geq 0 \\
& \qquad d_{\varepsilon}^{1} \geq 0, d_{\varepsilon}^{2} \geq 0 .
\end{aligned}
$$

The first constraint has the Lagrange multiplier $\beta \phi_{+1}^{1} \lambda_{\varepsilon}^{11}$ and states that the FI cannot spend more of currency 1 than it has. The second constraint has the Lagrange multiplier $\beta \phi_{+1}^{2} \lambda_{\varepsilon}^{12}$ and states that the FI cannot spend more of currency 2 than it has. The third and fourth constraint have the Lagrange multipliers $\beta \phi_{+1}^{1} \lambda_{d}^{11}$ and $\beta \phi_{+1}^{1} \lambda_{d}^{12}$ and state that the FI cannot borrow at the deposit facility of either central bank. Note, for a FI that accesses money market $1, q^{12}=0$, since this FI does not acquire currency 2 .

For $\rho_{d}^{1}>\rho_{m}^{1}>\rho_{\ell}^{1}$, FI are better off by borrowing or lending in the money market instead of lending or borrowing from the central bank. If $\rho_{d}^{1}=\rho_{m}^{1}$, FI that want to lend currency 1 are indifferent between the money market and the deposit facility at the central bank. And consequently, for $\rho_{m}^{1}=\rho_{\ell}^{1}$, FI that want to borrow currency 1 are indifferent between borrowing in the money market or from the central bank. Naturally, the same reasoning holds for FI who want to borrow in money market 2 .

Furthermore, if an FI has chosen to access money market 1, it must be that accessing money market 1 yields the highest value for that FI or that the FI is indifferent. If accessing the money market yields the highest value for this FI, it is not optimal to borrow part of the required money in money market 2 or access the central bank lending or deposit facilities in either country. If the FI is indifferent between borrowing in money market 1 or money market 2, I assume they always choose the domestic money market. Lastly, if the FI is indifferent between the money market or the standing facilities at the central bank, I assume they adjust their currency holdings in the money market. Either case implies $\ell_{\varepsilon}^{j}=d_{\varepsilon}^{j}=0$ for $j=1,2$ and $z_{\varepsilon}^{2}=0$, if borrowers choose to borrow in money market 1 .

Using Equation (5), the first-order conditions satisfy

$$
\begin{array}{cc}
\varepsilon u^{\prime}\left(q_{\varepsilon}\right)-\beta \phi_{+1}^{1} p^{11}\left(1+\lambda_{\varepsilon}^{11}\right) & =0 \\
\left(1+\lambda_{\varepsilon}^{11}\right)-\frac{1}{\rho_{m}^{1}} & =0 .
\end{array}
$$

Denote $V_{M}^{12}\left(m^{1}\right)$ the value of an $\varepsilon$-FI that accessed money market 2. The maximization 
problem for a $\varepsilon$-FI, that chose to enter money market 2 is

$$
\begin{aligned}
& V_{M}^{12}\left(m^{1}\right)=\max _{q_{\varepsilon}^{11}, q_{\varepsilon}^{12}, z_{\varepsilon}^{2}} \varepsilon u\left(q_{\varepsilon}\right) \\
& +\beta V_{S}\left(m^{1}+\ell_{\varepsilon}^{1}-p^{11} q_{\varepsilon}^{11}-d_{\varepsilon}^{1}, z_{\varepsilon}^{2}+\ell_{\varepsilon}^{2}-\frac{p^{12}}{e_{+1}} q_{\varepsilon}^{12}-k_{b}^{2}-d_{\varepsilon}^{2}, \ell_{\varepsilon}^{1}, \ell_{\varepsilon}^{2}, d_{\varepsilon}^{1}, d_{\varepsilon}^{2}, z_{\varepsilon}^{1}, z_{\varepsilon}^{2}\right) . \\
& \text { s.t. } m^{1}+\ell_{\varepsilon}^{1}-p^{11} q_{\varepsilon}^{11}-d_{\varepsilon}^{1} \geq 0, z_{\varepsilon}^{2}+\ell_{\varepsilon}^{2}-\frac{p^{12}}{e_{+1}} q_{\varepsilon}^{12}-k_{b}^{2}-d_{\varepsilon}^{2} \geq 0, \\
& d_{\varepsilon}^{1} \geq 0, d_{\varepsilon}^{2} \geq 0 .
\end{aligned}
$$

The first and second constraint implies that a FI cannot spend more than their currency 1 and currency 2 holdings. They have the Lagrange multiplier $\beta \phi_{+1}^{1} \lambda_{\varepsilon}^{21}$ and $\beta \phi_{+1}^{2} \lambda_{\varepsilon}^{22}$, respectively. The third and fourth constraints imply that a FI cannot borrow at the deposit facility of the central bank and have the Lagrange multipliers $\beta \phi_{+1}^{1} \lambda_{d}^{21}$ and $\beta \phi_{+1}^{1} \lambda_{d}^{22}$, respectively. Note, the same reasoning as above is true for borrowing and lending at the central bank and therefore $\ell^{j}=d^{j}=0 j=1,2$ for FI that choose to access money market 2. The first-order conditions satisfy

$$
\begin{array}{cc}
\varepsilon u^{\prime}\left(q_{\varepsilon}\right)-\beta \phi_{+1}^{1} p^{11}\left(1+\lambda_{\varepsilon}^{11}\right) & =0, \\
\varepsilon u^{\prime}\left(q_{\varepsilon}\right)-\beta \phi_{+1}^{1} p^{12}\left(1+\lambda_{\varepsilon}^{12}\right) & =0, \\
\left(1+\lambda_{\varepsilon}^{12}\right)-\frac{1}{\rho_{m}^{2}} & =0 .
\end{array}
$$

Lemma 1 characterizes the optimal quantities consumed by FI and the optimal quantities borrowed or lent in money market 1 or 2 .

Lemma 1. There exist two critical values $\varepsilon_{d}^{1}, \varepsilon_{M}^{1}$ for country 1 FI. If $\rho_{m}^{1} / \rho_{d}^{1} \geq \rho_{m}^{2} / \rho_{d}^{2}$, then a FI with $0 \leq \varepsilon \leq \varepsilon_{d}^{1}$ lends currency 1 in money market 1 and a FI with $\varepsilon>\varepsilon_{d}^{1}$ borrows currency 1 in money market 1 . If $\rho_{m}^{1} / \rho_{d}^{1}<\rho_{m}^{2} / \rho_{d}^{2}$, then a FI with $0 \leq \varepsilon \leq \varepsilon_{d}^{1}$ lends currency 1 in money market 1 , a FI with $\varepsilon_{d}^{1}<\varepsilon \leq \varepsilon_{M}^{1}$ borrows currency 1 in money market 1 and a FI with $\varepsilon>\varepsilon_{M}^{1}$ borrows currency 2 in money market 2 . The critical values $\varepsilon_{d}^{1}, \varepsilon_{M}^{1}$ satisfy

$$
\begin{aligned}
\varepsilon_{d}^{1} & =\frac{m^{1}}{p^{11} \frac{\rho_{d}^{1}}{\rho_{m}^{1}}} \\
\varepsilon_{M}^{1} & =\frac{\beta \phi_{+1}^{2} \frac{k_{b}^{2}}{\rho_{m}^{2}}}{\log \left(\frac{\rho_{m}^{2}}{\rho_{d}^{2}}\right)-\log \left(\frac{\rho_{m}^{1}}{\rho_{d}^{1}}\right)} .
\end{aligned}
$$


The quantity borrowed and lent by a FI in the money market with liquidity shock $\varepsilon$ and the quantity of goods consumed by the FI satisfy:

$$
q_{\varepsilon}=\varepsilon \frac{\rho_{m}^{1}}{\rho_{d}^{1}}, z_{\varepsilon}^{1}=p^{11} \frac{\rho_{m}^{1}}{\rho_{d}^{1}}\left(\varepsilon-\varepsilon_{d}^{1}\right), \forall \varepsilon,
$$

if $\rho_{m}^{1} / \rho_{d}^{1} \geq \rho_{m}^{2} / \rho_{d}^{2}$. The quantity borrowed and lent by a FI in the money market with liquidity shock $\varepsilon$ and the quantity of goods consumed by the FI satisfy:

$$
\begin{array}{llll}
q_{\varepsilon}=\varepsilon \frac{\rho_{m}^{1}}{\rho_{d}^{1}}, & z_{\varepsilon}^{1}=p^{11} \frac{\rho_{m}^{1}}{\rho_{d}^{1}}\left(\varepsilon-\varepsilon_{d}^{1}\right) & z_{\varepsilon}^{2}=0, & \text { if } 0 \leq \varepsilon \leq \varepsilon_{M}^{1}, \\
q_{\varepsilon}=\varepsilon \frac{\rho_{m}^{2}}{\rho_{d}^{2}}, & z_{\varepsilon}^{1}=m^{1}, & z_{\varepsilon}^{2}=\frac{p^{12}}{e_{+1}} \frac{\rho_{m}^{2}}{\rho_{d}^{2}} \varepsilon+k_{b}^{2} & \text { if } \varepsilon>\varepsilon_{M}^{1},
\end{array}
$$

if $\rho_{m}^{1} / \rho_{d}^{1}<\rho_{m}^{2} / \rho_{d}^{2}$.

The proof of Lemma 1 can be found in Appendix C.2. For the remainder of this paper, I make the following assumption:

Assumption 2. The cost of accessing the foreign money market $k_{b}^{2}$ satisfies

$$
k_{b}^{2}>\underline{k_{b}^{2}}=\varepsilon_{d}^{1}\left(\log \left(\frac{\rho_{m}^{2}}{\rho_{d}^{2}}\right)-\log \left(\frac{\rho_{m}^{1}}{\rho_{d}^{1}}\right)\right) \frac{\rho_{m}^{2}}{\beta \phi_{+1}^{2}} .
$$

Assumption 2 guarantees that $\varepsilon_{M}^{1}>\varepsilon_{d}^{1}$. Note, if this inequality does not hold, there might exist some FI that lend out money but would prefer to do so in the foreign money market. Since these FI only hold domestic currency, this is not possible.

I now discuss the implications of Lemma 1. As described above, the quantities consumed depend on the ratio of the money market rate and the deposit rate in the respective currency. Intuitively, FI choose the optimal quantity to consume based on the cost of borrowing a currency and the benefit of holding a currency across periods. If this ratio is equal to one (i.e. the marginal cost is equal to the marginal benefit), FI are able to consume a quantity that is equal to the first-best allocation. The difference in this ratio between the two currencies is also the reason why some FI might choose to acquire currency 2. If the ratio between the money market rate and the deposit rate is higher for one currency, FI have an incentive to switch to this currency, because it will allow them to consume a higher quantity. I now discuss each case.

Case: $\rho_{m}^{1} / \rho_{d}^{1} \geq \rho_{m}^{2} / \rho_{d}^{2}$. Figure 3 depicts the consumption schedule for FI in the case $\rho_{m}^{1} / \rho_{d}^{1} \geq \rho_{m}^{2} / \rho_{d}^{2}$. As stated above, in the first-best allocation each FI consumes a quantity of goods equal to their $\varepsilon$. Thus, the $45^{\circ}$ line represents the quantities consumed in the 


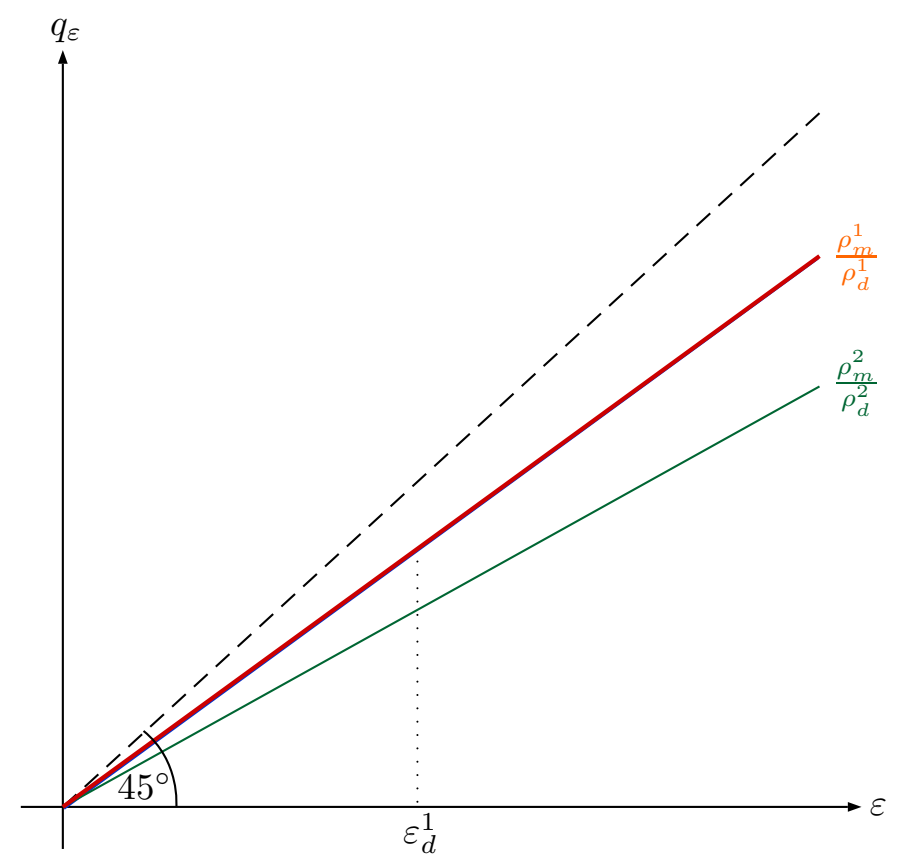

Figure 3: Consumption if $\rho_{m}^{1} / \rho_{d}^{1} \geq \rho_{m}^{2} / \rho_{d}^{2}$

first-best allocation. If $\rho_{m}^{1} / \rho_{d}^{1} \geq \rho_{m}^{2} / \rho_{d}^{2}$, using currency 1 yields a higher utility because the FI can afford a larger quantity of the consumption good. As a result, no FI from country 1 chooses to access money market 2 . Further, FI with $0 \leq \varepsilon \leq \varepsilon_{d}^{1}$ supply currency 1 in money market 1 and FI with $\varepsilon>\varepsilon_{d}^{1}$ demand currency 1 in money market 1 .

Case: $\rho_{m}^{1} / \rho_{d}^{1}<\rho_{m}^{2} / \rho_{d}^{2}$. Figure 4 illustrates the consumption schedule of FI as a function of $\varepsilon$ if $\rho_{m}^{1} / \rho_{d}^{1}<\rho_{m}^{2} / \rho_{d}^{2}$. Again, the $45^{\circ}$ line represents the first-best allocation. A FI with $0 \leq \varepsilon \leq \varepsilon_{d}^{1}$ lends currency 1 in money market 1 . A FI with $\varepsilon_{d}^{1}<\varepsilon \leq \varepsilon_{M}^{1}$ needs to borrow money in order to purchase their desired quantity of consumption goods. It needs to borrow an amount small enough and thus remains in money market 1. A FI with $\varepsilon \geq \varepsilon_{M}^{1}$ wants to borrow an amount that is high enough, such that the benefit of using currency 2 outweighs the cost of accessing money market 2. By using currency 2, it can afford a higher quantity of the consumption good and therefore prefers to use currency 2 as a medium of exchange.

Figure 5 depicts the effect of a change in $\rho_{d}^{1}$ on the critical value $\varepsilon_{M}^{1}$ in partial equilibrium for the case $\rho_{m}^{1} / \rho_{d}^{1}<\rho_{m}^{2} / \rho_{d}^{2}$. Ceteris paribus, an increase in $\rho_{d}^{1}$ (i.e. a decrease the deposit rate $\left.i_{d}^{1}\right)$, shifts the value function $V_{m}^{11}\left(m^{1}\right)$ down, causing $\varepsilon_{M}^{1}$ to decrease to $\varepsilon_{M}^{1^{\prime}}$. The marginal benefit of holding currency 1 decreases while the marginal cost of borrowing currency 1 remains constant. As a result, currency 1 becomes relatively less attractive to hold and more FI choose to borrow in money market 2 . 


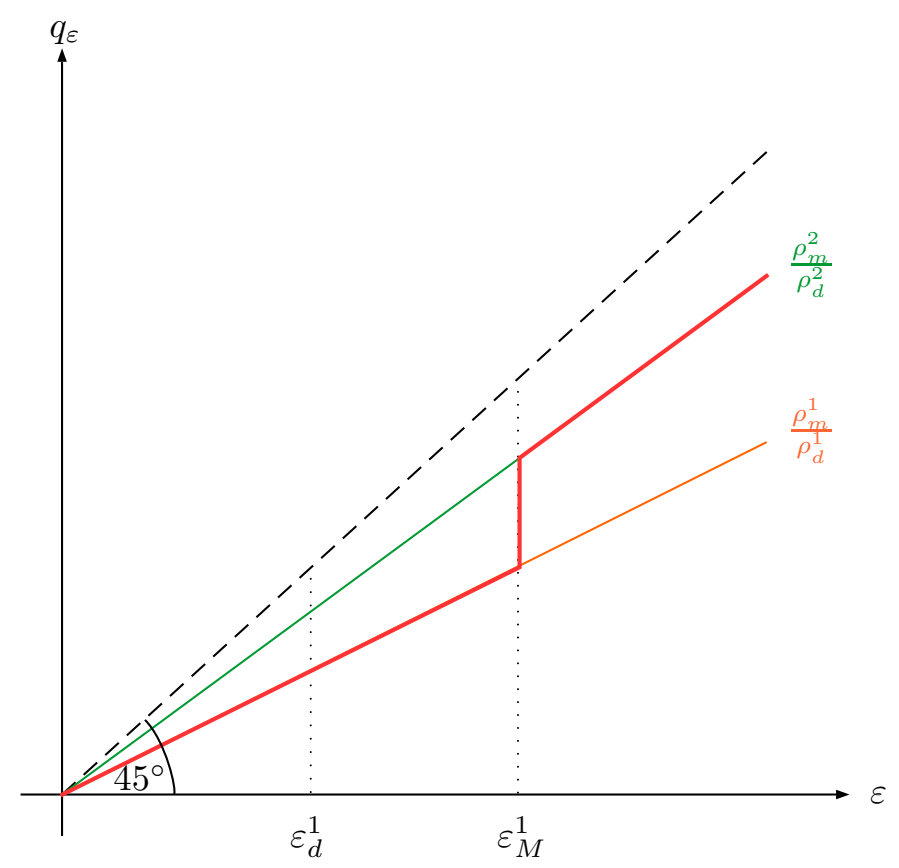

Figure 4: Consumption if $\rho_{m}^{1} / \rho_{d}^{1}<\rho_{m}^{2} / \rho_{d}^{2}$

\subsection{Equilibrium}

I focus on stationary and symmetric equilibria with a strictly positive demand for currency 1 and a strictly positive initial stock of currency 1 and currency $2, M_{0}^{j}>0$ for $j=1,2 .^{7}$ Denote $\gamma^{1}=M_{+1}^{1} / M^{1}$ the constant gross growth rate of the money stock in currency 1 . Such equilibria meet the following requirements: (i) the decisions of FI and sellers are optimal given prices; (ii) The decisions are symmetric across sellers and symmetric across FI with the same $\varepsilon$-shock; (iii) All markets clear; (iv) All real quantities remain constant over time; (v) The law of motion for the stock of currency 1 ,

$$
M_{+1}^{1}=M^{1}+\left(\frac{1}{\rho_{\ell}^{1}}-1\right) L^{1}-\left(\frac{1}{\rho_{d}^{1}}-1\right) D^{1}+\tau M^{1}
$$

holds in each period. $M_{+1}^{1}$ denotes the stock of currency 1 in period $t+1$. $L^{1}$ is the total amount that is borrowed at the central bank in country 1 and $D^{1}$ is the total amount of deposited at the central bank in country 1. Recall, $\tau M^{1}$ denotes lump-sum subsidies $(\tau>0)$ or lump-sum taxes $(\tau<0)$ levied by the central bank in country 1 .

\footnotetext{
${ }^{7}$ Since this is a nominal quantity, the central bank in each country can start the economy with one-time injections of currency $M_{0}^{j}$, for $j=1,2$ in period 0 .
} 


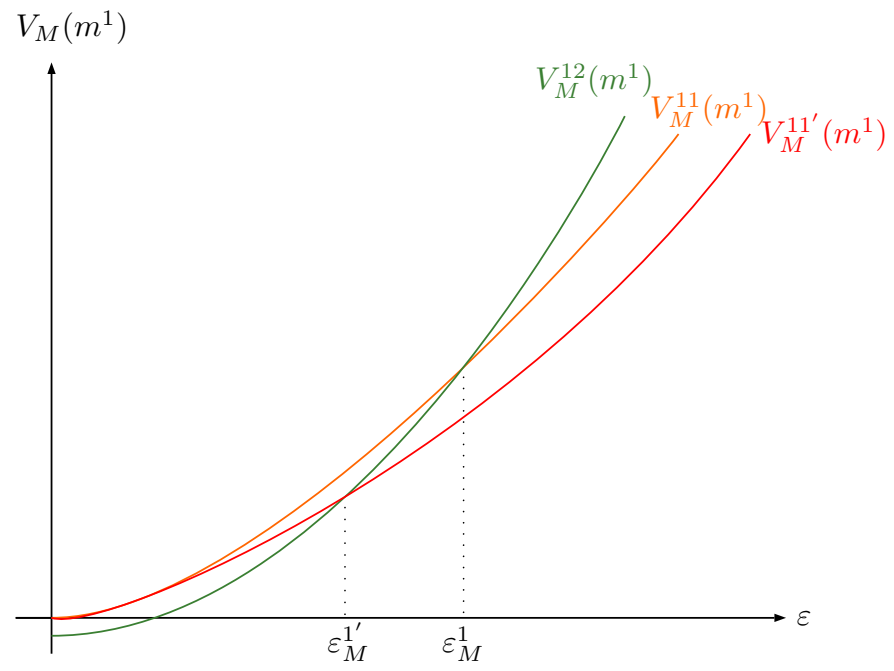

Figure 5: Value Functions of FI

Goods market clearing. Denote $q_{s}^{j k}$ the amount sold by sellers in country $j$ for currency $k$. For $\rho_{m}^{1} / \rho_{d}^{2}<\rho_{m}^{2} / \rho_{d}^{2}$ the goods market clearing conditions in country 1 satisfies

$$
\begin{aligned}
& q_{s}^{11}=\int_{0}^{\varepsilon_{M}^{1}}\left(\varepsilon \frac{\rho_{m}^{1}}{\rho_{d}^{1}}\right) d F(\varepsilon), \\
& q_{s}^{12}=\int_{\varepsilon_{M}^{1}}^{\infty}\left(\varepsilon \frac{\rho_{m}^{2}}{\rho_{d}^{2}}\right) d F(\varepsilon) .
\end{aligned}
$$

For $\rho_{m}^{1} / \rho_{d}^{1} \geq \rho_{m}^{2} / \rho_{d}^{2}$, the goods market clearing condition satisfies

$$
q_{s}^{11}=\int_{0}^{\infty}\left(\varepsilon \frac{\rho_{m}^{1}}{\rho_{d}^{1}}\right) d F(\varepsilon)
$$

Money market clearing. Denote $\left(\rho_{m}^{1}\right)^{u}$ the money market rate in market 1 that would result in equilibrium, if the money market rate were not affected by the standing facilities $\left(\rho_{\ell}^{1}, \rho_{d}^{1}\right)$. Supply and demand are characterized by

$$
\begin{aligned}
& S^{1}\left(\left(\rho_{m}^{1}\right)^{u}\right)=\int_{0}^{\varepsilon_{d}^{1}} p^{11} \frac{\left(\rho_{m}^{1}\right)^{u}}{\rho_{d}^{1}}\left(\varepsilon_{d}^{1}-\varepsilon\right) d F(\varepsilon)+\int_{\varepsilon_{M}^{1}}^{\infty} m^{1} d F(\varepsilon), \\
& D^{1}\left(\left(\rho_{m}^{1}\right)^{u}\right)=\int_{\varepsilon_{d}^{1}}^{\varepsilon_{M}^{1}} p^{11} \frac{\left(\rho_{m}^{1}\right)^{u}}{\rho_{d}^{1}}\left(\varepsilon-\varepsilon_{d}^{1}\right) d F(\varepsilon)+n^{21} z^{21},
\end{aligned}
$$

for $\rho_{m}^{1} / \rho_{d}^{1}<\rho_{m}^{2} / \rho_{d}^{2}$. Recall, $n^{21} z^{21}$ denotes the constant amount that country 2 FI borrow in money market 1 . 
Thus, the money market clearing conditions is

$$
\int_{0}^{\varepsilon_{d}^{1}} p^{11} \frac{\left(\rho_{m}^{1}\right)^{u}}{\rho_{d}^{1}}\left(\varepsilon_{d}^{1}-\varepsilon\right) d F(\varepsilon)+\int_{\varepsilon_{M}^{1}}^{\infty} m^{1} d F(\varepsilon)=\int_{\varepsilon_{d}^{1}}^{\varepsilon_{M}^{1}} p^{11} \frac{\left(\rho_{m}^{1}\right)^{u}}{\rho_{d}^{1}}\left(\varepsilon-\varepsilon_{d}^{1}\right) d F(\varepsilon)+n^{21} z^{21} .
$$

For $\rho_{m}^{1} / \rho_{d}^{1} \geq \rho_{m}^{2} / \rho_{d}^{2}$, money market supply and demand are characterized by

$$
\begin{aligned}
S^{1}\left(\left(\rho_{m}^{1}\right)^{u}\right) & =\int_{0}^{\varepsilon_{d}^{1}} p^{11} \frac{\left(\rho_{m}^{1}\right)^{u}}{\rho_{d}^{1}}\left(\varepsilon_{d}^{1}-\varepsilon\right) d F(\varepsilon), \\
D^{1}\left(\left(\rho_{m}^{1}\right)^{u}\right) & =\int_{\varepsilon_{d}^{1}}^{\infty} p^{11} \frac{\left(\rho_{m}^{1}\right)^{u}}{\rho_{d}^{1}}\left(\varepsilon-\varepsilon_{d}^{1}\right) d F(\varepsilon)+n^{21} z^{21} .
\end{aligned}
$$

And in this case, the money market clearing conditions is

$$
\int_{0}^{\varepsilon_{d}^{1}} p^{11} \frac{\left(\rho_{m}^{1}\right)^{u}}{\rho_{d}^{1}}\left(\varepsilon_{d}^{1}-\varepsilon\right) d F(\varepsilon)=\int_{\varepsilon_{d}^{1}}^{\infty} p^{11} \frac{\left(\rho_{m}^{1}\right)^{u}}{\rho_{d}^{1}}\left(\varepsilon-\varepsilon_{d}^{1}\right) d F(\varepsilon)+n^{21} z^{21} .
$$

Rewriting the money market clearing condition for both cases yields

$$
\rho_{m}^{1}= \begin{cases}\rho_{d}^{1}, & \text { if } D^{1}\left(\rho_{d}^{1}\right)<S^{1}\left(\rho_{d}^{1}\right) \\ \rho_{\ell}^{1}, & \text { if } D^{1}\left(\rho_{\ell}^{1}\right)>S^{1}\left(\rho_{\ell}^{1}\right) \\ \left(\rho_{m}^{1}\right)^{u}, & \text { otherwise. }\end{cases}
$$

Proposition 2. If $\rho_{m}^{1} / \rho_{d}^{1}<\rho_{m}^{2} / \rho_{d}^{2}$, then a symmetric and stationary equilibrium with a positive demand for reserves is a policy $\left(\rho_{d}^{1}, \rho_{\ell}^{1}\right)$ and endogenous variables $\left(\varepsilon_{d}^{1}, \varepsilon_{M}^{1}, \rho_{m}^{1}\right)$ satisfying Equations (13), (21), and

$$
\frac{\gamma^{1} \rho_{d}^{1}}{\beta}=\int_{0}^{\varepsilon_{M}^{1}} \frac{\rho_{d}^{1}}{\rho_{m}^{1}} d F(\varepsilon)+\int_{\varepsilon_{M}^{1}}^{\infty} \frac{\rho_{d}^{2}}{\rho_{m}^{2}} d F(\varepsilon)
$$

If $\rho_{m}^{1} / \rho_{d}^{1} \geq \rho_{m}^{2} / \rho_{d}^{2}$, then a symmetric and stationary equilibrium with a positive demand for reserves is a policy $\left(\rho_{d}^{1}, \rho_{\ell}^{1}\right)$ and endogenous variables $\left(\varepsilon_{d}^{1}, \rho_{m}^{1}\right)$ satisfying Equations (21), and

$$
\frac{\gamma^{1} \rho_{d}^{1}}{\beta}=\int_{0}^{\infty} \frac{\rho_{d}^{1}}{\rho_{m}^{1}} d F(\varepsilon)
$$

The proof of Proposition 2 is in Appendix C.2. I will refer to the equilibrium where only currency 1 is used (i.e. $\rho_{m}^{1} / \rho_{d}^{1} \geq \rho_{m}^{2} / \rho_{d}^{2}$ ) as a type I equilibrium and the equilibrium where two currencies are used (i.e. $\rho_{m}^{1} / \rho_{d}^{1}<\rho_{m}^{2} / \rho_{d}^{2}$ ) as a type II equilibrium.

In a type I equilibrium, Equation (23) pins down the money market rate $\rho_{m}^{1}$ and Equation (21) pins down $\varepsilon_{d}^{1}$ and therefore the real value of currency $1, m^{1} / p^{11}$. The 
remainder of the variables are determined as follows: The exchange rate is determined according to Equation (1). Equation (6) determines $\phi_{+1}^{1}$. The quantities consumed and borrowed in the money market are determined by Lemma 1 . The total amount produced is determined by Equation (18).

In a type II equilibrium, Equations (13), (21) and (22) pin down endogenous variables $\left(\varepsilon_{d}^{1}, \varepsilon_{M}^{1}, \rho_{m}\right)$. The remainder of the variables are determined as follows: Equation (6) pins down $\phi_{+1}^{1}$ and price $p^{12}$. Lemma (1) determines the quantities consumed. Equation (17) determines the total quantity produced by sellers and Equation (1) determines the exchange rate.

Further, in both types of equilibria, the clearing condition for money holdings of currency 1 has to hold, $\int_{0}^{\infty} m^{1} d F(\varepsilon)=m^{1}$ or $m^{1}=M^{1}$. It is further useful to normalize $M^{1}=1$, such that $\varepsilon_{d}^{1}$ determines the price level $1 / p^{11}$.

\subsection{Optimal monetary policy}

Proposition 3. The optimal policy is $\rho_{d}^{1}=\frac{\beta}{\gamma^{1}}$. Under this policy, $\rho_{m}^{1}=\rho_{d}^{1}$ must hold. Therefore, the optimal policy implements the first-best allocation.

The proof of Proposition 3 is in Appendix C.2. The central bank can implement the first-best allocation by setting $\rho_{d}^{1}=\frac{\beta}{\gamma^{1}}$. Note, this policy is not unique, as the optimal monetary policy does not specify $\rho_{\ell}^{1}$. Any $\rho_{\ell}^{1} \leq \rho_{d}^{1}=\beta / \gamma^{1}$ would implement the first-best allocation.

Furthermore, Proposition 3 does not eliminate the possibility that NIR can be optimal. If $\beta / \gamma^{1}>1$, then the optimal policy requires $\rho_{d}^{1}>1$, which implies a negative deposit rate at the central bank. This would be the case if the economy experiences a deflation.

\section{Discussion}

\subsection{Monetary policy}

Here, I discuss the effects of monetary policy on the exchange rate. I restrict the discussion to cases where $\rho_{d}^{1} \geq \rho_{m}^{1}>\rho_{\ell}^{1}$, such that Equations (20) or (19) hold.

\section{Type I Equilibria}


Proposition 4. In a type I equilibrium, the real value of currency $1, \phi^{1} m^{1}$ satisfies

$$
\phi^{1} m^{1}=\int_{0}^{\infty} \varepsilon d F(\varepsilon)+n^{21} z^{21} .
$$

The proof of Proposition 4 is in Appendix C.2. Proposition 4 implies that the value of currency 1 does not depend on the interest rate of the deposit facility, but on the expected liquidity needs and the demand for domestic currency coming from foreign agents. This implies that the decision how much currency 1 to acquire does not depend on prices and therefore also not on the deposit rate. Thus, a decrease in the deposit rate, given that $\rho_{m}^{1} / \rho_{d}^{1} \geq \rho_{m}^{2} / \rho_{d}^{2}$ continues to hold, will not affect the value of currency 1 and therefore also not the exchange rate. To see this, note that from Equation (23), the money market rate will always adjust such that $\gamma^{1} \rho_{m}^{1} / \beta=1$ holds. Thus, the money market rate is pinned down by cost of carrying money across periods $\gamma^{1} / \beta$ and not by the deposit rate. ${ }^{8}$ As a consequence, a change in the deposit rate does not affect the choice of currency 1 holdings. Moreover, from Equation (6), the price of consumption good in the investment market changes proportionally to the decrease in the deposit rate. Thus, from Lemma 1, the quantities consumed also decrease proportionally. As a result, FI consume less. However as long as $\rho_{m}^{1} / \rho_{d}^{1} \geq \rho_{m}^{2} / \rho_{d}^{2}$ continues to hold, FI still prefer to use currency 1 only.

There are two comments in order. First, this result depends crucially on the fact that FI have no upper bound in the amount they can borrow in the money market. If FI had an upper bound on how much they can borrow in the money market, then the decision of much currency 1 to bring into the money and goods market would depend on how much goods FI can receive for the amount they can borrow if they are constrained. This depends on the price of the goods in the goods market and therefore on the deposit rate. In such a scenario, a decrease in the deposit rate would imply a decrease in the real value of currency 1 and would therefore imply a deprecation against currency 2. Second, as shown in Proposition 4, the real value of currency 1 also depends on the demand from foreign FI. Since the demand is assumed to be constant in order to focus on domestic money demand, this does not affect the value of currency 1 . However, if the decrease in $\rho_{m}^{1} / \rho_{d}^{1}$ would imply that there is a decrease in the demand from foreign FI to use currency 1, then currency 1 would also depreciate.

Type II Equilibria Recall that $\rho_{k}^{j}=1 /\left(1+i_{k}^{j}\right)$ for $j=1,2$ and $k=m, d, \ell$. In order to discuss the effects of a decrease in the interest rate on reserves in equilibrium, I take the total derivative of the system of equations that define an equilibrium, namely, Equations

\footnotetext{
${ }^{8}$ Note if, $\rho_{\ell}^{1}>\beta / \gamma^{1}$ or $\beta / \gamma^{1}>\rho_{d}^{1}$, then there exists no type I equilibrium. In other words, if the money market rate cannot adjust to satisfy $\gamma^{1} \rho_{m}^{1} / \beta=1$, because the upper or lower bound of the money market rate prohibit this, there exists no type I equilibrium.
} 
(22), (13) and (21). Denote $\Delta=\log \left(\rho_{m}^{2} / \rho_{d}^{2}\right)-\log \left(\rho_{m}^{1} / \rho_{d}^{1}\right)$.

Taking the total derivative of Equations (13) yields

$$
\frac{d \varepsilon_{M}^{1}}{d \rho_{d}^{1}}=\frac{\varepsilon_{M}^{1}}{\Delta}\left[\frac{d \rho_{m}^{1}}{d \rho_{d}^{1}} \frac{1}{\rho_{m}^{1}}-\frac{1}{\rho_{d}}\right] \gtrless 0 .
$$

Taking the total derivative of Equation (22) and using Equation (25) yields

$$
\frac{d \rho_{m}^{1}}{d \rho_{d}^{1}}=\frac{\frac{1}{\rho_{d}^{1}} \int_{\varepsilon_{M}^{1}}^{\infty} \frac{\rho_{d}^{2}}{\rho_{m}^{2}} d F(\varepsilon)+\frac{\varepsilon_{M}^{1}}{\Delta} f\left(\varepsilon_{M}^{1}\right)\left(\frac{\rho_{d}^{1}}{\rho_{m}^{1}}-\frac{\rho_{d}^{2}}{\rho_{m}^{2}}\right) \frac{1}{\rho_{d}^{1}}}{\frac{\varepsilon_{M}^{1}}{\Delta} f\left(\varepsilon_{M}^{1}\right)\left(\frac{\rho_{d}^{1}}{\rho_{m}^{1}}-\frac{\rho_{d}^{2}}{\rho_{m}^{2}}\right)\left(\frac{1}{\rho_{m}^{1}}\right)-\int_{0}^{\varepsilon_{M}^{1}} \frac{\rho_{d}^{1}}{\left(\rho_{m}^{1}\right)^{2}} d F(\varepsilon)} \gtrless 0,
$$

The money market rate $\rho_{m}^{1}$ is increasing in $\rho_{d}^{1}$ if

$$
\frac{\left(\frac{\rho_{d}^{1}}{\rho_{m}^{1}}-\frac{\rho_{d}^{2}}{\rho_{m}^{2}}\right)}{\frac{\rho_{d}^{1}}{\rho_{m}^{1}}}>\frac{\int_{0}^{\varepsilon_{M}^{1}} d F(\varepsilon)}{\frac{\varepsilon_{M}^{1}}{\Delta} f\left(\varepsilon_{M}^{1}\right)} .
$$

Finally, taking the total derivative of Equation (20) to study the effect on the critical value $\varepsilon_{d}^{1}$ yields

$$
\frac{d \varepsilon_{d}^{1}}{d \rho_{d}^{1}}=\frac{f\left(\varepsilon_{M}^{1}\right) \frac{\left(\varepsilon_{M}^{1}\right)^{2}}{\Delta}\left[\frac{d \rho_{m}^{1}}{\rho_{d}^{1}} \frac{1}{\rho_{m}^{1}}-\frac{1}{\rho_{d}^{1}}\right]}{\int_{0}^{\varepsilon_{M}^{1}} \varepsilon / \varepsilon_{d}^{1} d F(\varepsilon)} \gtrless 0 .
$$

Recall, $\varepsilon_{d}^{1}$ is proportional to the real value of currency $1 \mathrm{~m}^{1} / \mathrm{p}^{11}$. Equations (25) and (28) show that the demand for currency 1 and thus the exchange rate as well as the number of FI that choose to acquire currency 2 crucially depend on $d \rho_{m}^{1} / d \rho_{d}^{1}$.

Therefore, I now discuss the effects on a decrease on the exchange rate for different cases of $d \rho_{m}^{1} / d \rho_{d}^{1}$.

Case $d \rho_{m}^{1} / d \rho_{d}^{1}<0$ : If $d \rho_{m}^{1} / d \rho_{d}^{1}<0$, then Equations (28), (25) and (26) are negative. Figure 6 illustrates the case when $\rho_{m}^{1} / \rho_{d}^{1}$ decreases to $\rho_{m}^{1^{\prime}} / \rho_{d}^{1^{\prime}}$. The $45^{\circ}$ line indicates the first-best allocation. In this case, the decrease in the deposit rate leads to a decrease in the ratio $\rho_{m}^{1} / \rho_{d}^{1}$ and thus decreases the incentive to acquire currency 1 . As a result, FI demand less currency 1 holdings in the settlement and foreign exchange market and the currency depreciates. Moreover, more FI choose to use currency 2 as a means of payment and $\varepsilon_{M}^{1}$ decreases to $\varepsilon_{M}^{1^{\prime}}$. The decrease in $\varepsilon_{M}^{1}$ can be interpreted as an increase in capital outflow as more domestic FI choose to hold foreign currency. Note, this case occurs if Equation (27) does not hold. In other words if the difference between $\rho_{m}^{1} / \rho_{d}^{1}$ and $\rho_{m}^{2} / \rho_{d}^{2}$ is relatively small, a decrease in the deposit rate leads to an deprecation of the domestic currency and an increase in capital outflow. 


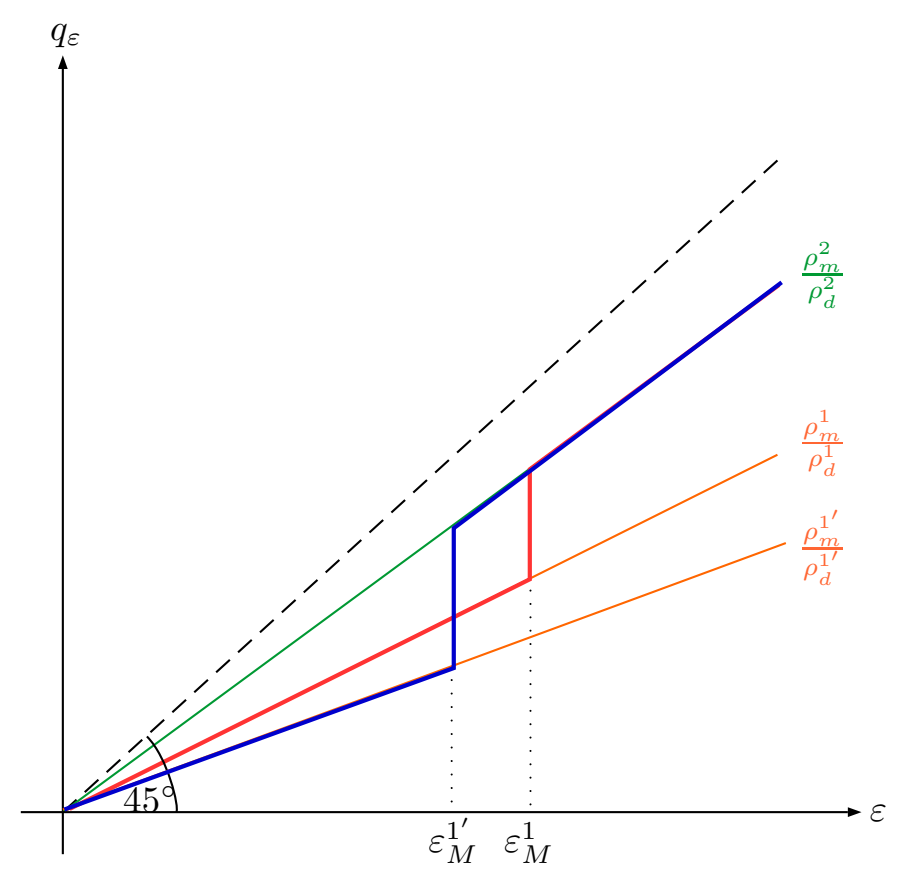

Figure 6: Consumption if $d \rho_{m}^{1} / d \rho_{d}^{1}<0$

Case $d \rho_{m}^{1} / d \rho_{d}^{1}>1$ : First, note that if Equation (27) holds, $d \rho_{m}^{1} / d \rho_{d}^{1}>1$ must hold. Thus, if $d \rho_{m}^{1} / d \rho_{d}^{1}>1$, both critical values $\varepsilon_{M}^{1}$ and $\varepsilon_{d}^{1}$ increase with a decrease in the deposit rate $i_{d}$, leading to an appreciation of currency 1. Figure 7 illustrates this case, given that $\rho_{m}^{1} / \rho_{d}^{1}<\rho_{m}^{2} / \rho_{d}^{2}$ continues to hold. Again, the $45^{\circ}$ line indicates the first-best allocation. If the ratio between the money market rate and the deposit rate increases due to a decrease in the deposit rate, currency 1 becomes relatively more attractive to use as a means of payment and as result, it appreciates. Moreover, less FI choose to borrow currency 2 , leading to an increase in the critical value $\varepsilon_{M}^{1}$ to $\varepsilon_{M}^{1^{\prime}}$. This can be interpreted as a decrease in the capital outflow. This case occurs if Equation (27) holds. In other words, if the difference between $\rho_{m}^{1} / \rho_{d}^{1}$ and $\rho_{m}^{2} / \rho_{d}^{2}$ is large, a decrease in the deposit rate cause an appreciation of currency 1 and a decrease in capital outflow.

To sum up, the effect of a decrease on the deposit rate $i_{d}^{1}$ crucially depends on the ratio between the marginal cost of borrowing and the marginal benefit of holding a currency. If a decrease in $i_{d}^{1}$ causes a decrease in the ratio, then currency 1 becomes less attractive to hold and depreciates. Moreover, more FI choose to use currency 2, resulting in an increase in capital outflow. On the other hand, if a decrease in $i_{d}^{1}$ causes an increase in the ratio, currency 1 appreciates and less FI choose to use currency 2 as a means of payment leading to a decrease in capital outflow. Note that these results do not depend on the sign of the deposit rate and the money market rate. The ratios $\rho_{m}^{1} / \rho_{d}^{1}$ and $\rho_{m}^{2} / \rho_{d}^{2}$ determine money demand for currency 1 , the critical value $\varepsilon_{M}^{1}$ and the exchange rate. This holds 


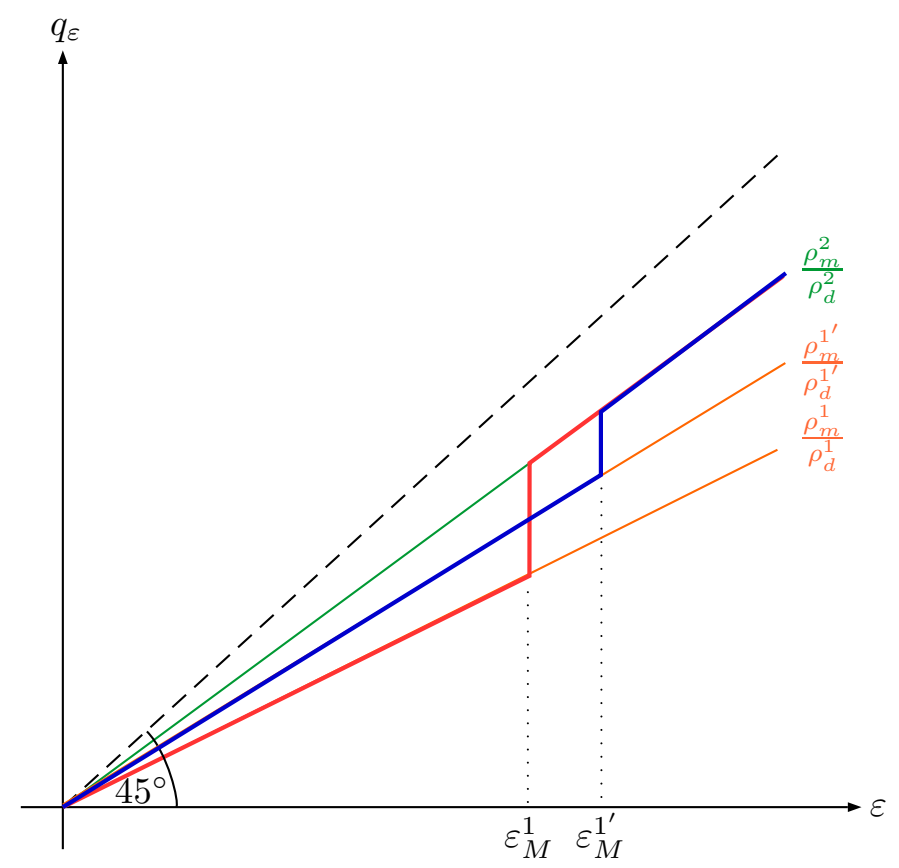

Figure 7: Consumption if $d \rho_{m}^{1} / d \rho_{d}^{1}>\rho_{d}^{1} / \rho_{m}^{1}$

with positive rates and NIR.

\subsection{Limited pass-through to bank deposit rates}

In the theoretical framework, I assume that sellers have access to the deposit facility of the central bank. Another way to interpret this assumption is that sellers have bank accounts with FI but receive the same interest rate on their deposits as the interest rate on the deposit facility of the central bank. However, there are several observations in the recent NIR literature that show a limited pass-through of NIR to bank deposit rates. Here, I extend the benchmark model to study the implications of a limited pass-trough to bank deposit rates during NIR periods. The maximization problems can be found in Appendix C.1. In the following discussion, I just state the results. I assume that sellers deposit their earnings at the very end of the goods market at their bank accounts and that sellers deposit currency 1 with country 1 FI and currency 2 with country 2 FI for simplicity. Furthermore, I assume that sellers are equally distributed among FI such that the amount of deposits that each FI receives at the end of the goods market is identical across all FI. ${ }^{9}$ Denote $1 / \rho_{s}^{j}=\left(1+i_{s}^{j}\right)$ the price of one unit deposited with a FI, where $i_{s}^{j}$ is the interest rate on bank deposits in currency $j$ for $j=1,2$.

Lemma 5 implies that the relevant ratio for the choice of which currency to acquire is

\footnotetext{
${ }^{9}$ Here, I follow Berentsen and Ruprecht, 2020.
} 
now $\rho_{m}^{j} / \rho_{s}^{j}$ for $j=1,2$. As in the benchmark model, if $\rho_{m}^{1} / \rho_{s}^{1} \geq \rho_{m}^{2} / \rho_{s}^{2}$, then FI only use currency 1 as a means of payment and a decrease in the central bank deposit rate does not affect the demand for currency 1 or the exchange rate. If $i_{s}^{1}=i_{s}^{2}=0$ holds in both countries, then $\rho_{m}^{1} / \rho_{s}^{1} \geq \rho_{m}^{2} / \rho_{s}^{2}$ implies that $i_{m}^{1}<i_{m}^{2}$. Thus, if country 1 has a lower money market rate, the central bank cannot affect the exchange rate by lowering the central bank deposit rate.

For the following discussion I focus on the case where $\rho_{m}^{1} / \rho_{s}^{1}<\rho_{m}^{2} / \rho_{s}^{2}$ holds. Denote $\varepsilon_{d^{\prime}}^{1}$, the critical value for which an FI is indifferent between borrowing and lending. Denote $\varepsilon_{M^{\prime}}^{1}$ the critical value for which an FI is indifferent between borrowing in money market 1 and borrowing in money market 2 .

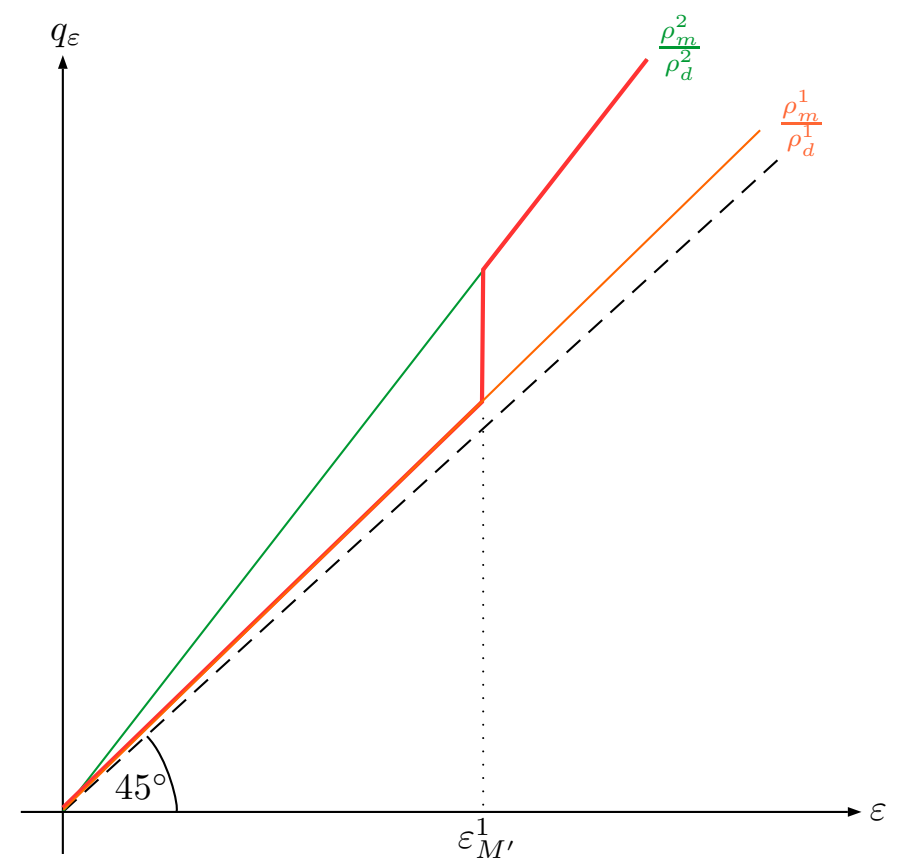

Figure 8: Consumption under limited pass-through

Consumption if $\rho_{m}^{1} / \rho_{s}^{1}<\rho_{m}^{2} / \rho_{s}^{2}$. Figure 8 illustrates the consumption schedule of country $1 \mathrm{FI}$ in this case. FI with $0 \leq \varepsilon \leq \varepsilon_{d^{\prime}}^{1}$ lend currency 1 in money market 1 , FI with $\varepsilon_{d^{\prime}}^{1} \leq \varepsilon \leq \varepsilon_{M^{\prime}}^{1}$ borrow currency 1 in money market 1 and FI with $\varepsilon>\varepsilon_{M^{\prime}}^{1}$ borrow currency 2 in money market 2 . Note, a negative money market rate and a zero retail deposit rate implies $\rho_{m}^{j} / \rho_{s}^{j}>1$ for $j=1,2$. Thus, FI now consume a higher amount compared to the first-best quantities. The reason is that FI have an incentive to increase the quantity consumed in order to avoid the NIR because they cannot pass on the NIR to their depositors. As discussed above, $\rho_{m}^{1} / \rho_{s}^{1}<\rho_{m}^{2} / \rho_{s}^{2}$ implies that $i_{m}^{1}>i_{m}^{2}$. FI with a liquidity preference choose to use currency 2 because the cost associated with entering the foreign 
money market is relatively small compared to the benefit of being able to borrow at a lower rate.

Effect of a change in $i_{d}^{1}$. From Equation (41), it is straightforward to see that a decrease in the deposit rate of the central bank only affects the money market rate if $\rho_{m}^{1}=\rho_{d}^{1}$. There are two cases to consider. First, if the central bank deposit rate is binding (i.e. the money market does not clear), then a decrease in the central bank deposit rate will lead to an decrease in the money market rate to the same extent. This implies $d \rho_{m}^{1} / d \rho_{d}^{1}=1$. The second case is, when the money market rate clears the money market at $\rho_{m}^{1}=\rho_{d}^{1}$. In that case, an interest rate cut will not have any effect and $d \rho_{m}^{1} / d \rho_{d}^{1}=0$. Thus, there is no corresponding effect on money demand in the settlement market and thus no effect on the exchange rate. In the following, paragraph, I discuss the first case.

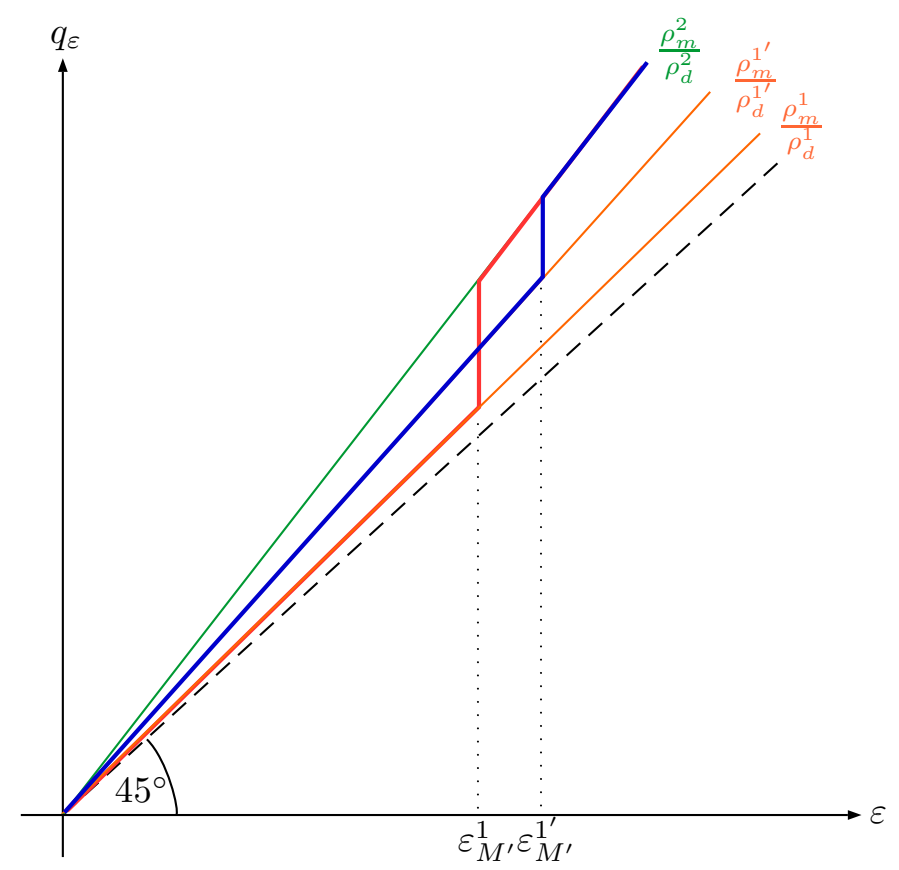

Figure 9: Consumption under limited pass-through

Effect of a decrease in $i_{d}^{1}$ if $d \rho_{m}^{1} / d \rho_{d}^{1}=1$. Figure 9 illustrates the effect of a change in $i_{d}^{1}$ if $d \rho_{m}^{1} / d \rho_{d}^{1}=1$. In this case, a decrease of the central bank deposit rate leads to a decrease in the rate in money market 1 to the same extent. Thus, the cost of borrowing currency 1 deceases, while the benefit of holding currency 1 remains constant. As a result, currency 1 becomes relatively more attractive to hold and appreciates. Moreover, the critical value $\varepsilon_{M^{\prime}}^{1}$ increases to $\varepsilon_{M^{\prime}}^{1^{\prime}}$ and thus, capital outflow decreases. 
This can also be seen by looking at the total derivative of Equation (36)

$$
\left.\frac{d \varepsilon_{M^{\prime}}^{1}}{d \rho_{d}^{1}}\right|_{\rho_{m}^{1}=\rho_{d}^{1}}=\frac{\int_{0}^{\varepsilon_{M^{\prime}}^{1}} \frac{\rho_{s}^{1}}{\left(\rho_{m}^{1}\right)^{2}} d F(\varepsilon)}{\left(\frac{\rho_{s}^{1}}{\rho_{m}^{1}}-\frac{\rho_{s}^{2}}{\rho_{m}^{2}}\right) f\left(\varepsilon_{M^{\prime}}^{1}\right)}>0
$$

if $d \rho_{m}^{1} / d \rho_{d}^{1}=1$. To look at the change in the value of currency 1 , I study the change in the supply of currency 1 in the money market (the RHS of Equation (41)). ${ }^{10}$ Taking the total derivative of the right-hand side of Equation (41) yields

$$
\left.\frac{d \varepsilon_{d^{\prime}}^{1}}{d \rho_{d}^{1}}\right|_{\rho_{m}^{1}=\rho_{d}^{1}}=\frac{\int_{0}^{\varepsilon_{M^{\prime}}^{1}} \frac{\rho_{s}^{1}}{\left(\rho_{m}^{1}\right)^{2}} d F(\varepsilon)}{\left(\frac{\rho_{s}^{1}}{\rho_{m}^{1}}-\frac{\rho_{s}^{2}}{\rho_{m}^{2}}\right) \int_{0}^{\varepsilon_{d^{\prime}}^{1}} \varepsilon /\left(\varepsilon_{d^{\prime}}^{1}\right)^{2} d F(\varepsilon)}>0
$$

if $d \rho_{m}^{1} / d \rho_{d}^{1}=1$.

The reason for this result is that without the corresponding decrease in the marginal benefit to hold currency 1 across periods for sellers, the ratio between the marginal cost of borrowing and the marginal benefit of holding currency 1 is always decreasing in $i_{m}^{1}$. As the money market rate decreases in country 1 , the ratio between the money market rate and the bank deposit rate increases, making currency 1 more attractive to hold. As a consequence, currency 1 appreciates and capital outflow decreases.

\subsection{Exit from NIR}

The results of the extension have interesting implications for an exit from NIR. In the benchmark model, increasing the central bank deposit rate causes an appreciation of the currency if the ratio between the money market rate and the central bank deposit rate increases. If however the ratio decreases with an increase in the central bank deposit rate, the currency will depreciate. However, in a NIR scenario where banks are confronted with a zero lower bound on deposits, the model predicts that the currency will depreciate with a decrease in the central bank deposit rate and a corresponding decrease in the money market rate. Given that most countries that implemented NIR are currently operating a so-called floor system where the money market rate is determined by the central bank deposit rate, these results might be relevant, if central banks are concerned about the effects of an exit from NIR on the exchange rate.

\footnotetext{
${ }^{10}$ Recall that in this case $\rho_{m}^{1}=\rho_{d}^{1}$ and the money market does not clear. To see how the value of currency 1 changes, I therefore look at the change in the supply in money market 1 , which is determined by the demand for currency 1 in the settlement and foreign exchange market.
} 


\section{Conclusion}

This paper develops a dynamic general equilibrium model to study the effect of NIR on exchange rates and capital flows. The theoretical framework shows that in the absence of a zero lower bound on retail deposit rates of banks, the effects of NIR on exchange rates and capital flows are not inherently different from positive interest rates.

The model suggests that the decisions of FI which currency to acquire crucially depend on the ratio between the money market rate and the central bank deposit rate. In an equilibrium, where domestic agents only use the domestic currency, a decrease in the deposit rate does not affect the exchange rate. However, if both currencies are used in equilibrium, monetary policy can affect the exchange rate. If a decrease in the deposit rate of the central bank leads to a decrease in the ratio between the money market rate and the deposit rate, the domestic currency depreciates and capital outflow increases. If, however, a decrease in the central bank deposit rate leads to an increase in the ratio between the money market rate and the deposit rate, the currency becomes more attractive to use as a means of payment. As a result, the currency appreciates and capital outflow decreases.

If FI cannot pass on the NIR to their retail deposit accounts, then the effects of a decrease in the central bank deposit rate differ. Namely, a decrease in the central bank deposit rate either leads to an appreciation of the domestic currency or has no effect at all. If FI only use the domestic currency or if the central bank deposit rate does not affect the money market rate, a decrease in the deposit rate will not affect exchange rates or capital flows. If central banks operate a floor system where the money market rate moves with the central bank deposit rate, then a decrease in the central bank deposit rate leads to an appreciation of the domestic currency and a decrease in capital outflow.

It's important to note that the model is a steady-state model and therefore the results correspond to effects that would occur over a prolonged period of NIR. There are some observations that suggest that this zero lower bound on retail deposits vanishes with a prolonged period of NIR as banks start to charge NIR to firms and wealthy customers, showing that the results of the benchmark model are still relevant in NIR periods.

The theoretical model has some limitations. It focuses on the domestic money demand by domestic agents and abstracts from the money demand for the domestic currency arising from foreign agents. Thus, results are likely to change to some extent if the money demand abroad is taken into consideration. For example if a decrease in the central bank deposit rate leads to a decrease in the ratio $\rho_{m}^{1} / \rho_{d}^{1}$, then not only would domestic agents be less willing to use currency 1 , but also foreign agents would use currency 1 less. Thus, the decrease in the demand for currency 1 is likely to be larger and would therefore have a larger 
effect on the exchange rate. Further, most central banks adopted NIR with exemption thresholds, which is not considered here. The level of these exemption thresholds can vary quite extensively across countries and may affect the relative attractiveness of different currencies. Thus, the exchange rate might also depend on the relative levels of these exemption thresholds. 


\section{Appendix A}

Here, I provide the formal analysis of the extension of the benchmark model discussed in Subsection 4.2. Recall, I assume that sellers deposit their earnings at the very end of the goods market at their bank accounts and that sellers deposit currency 1 with country 1 FI and currency 2 with country 2 FI for simplicity. Furthermore, I assume that sellers are equally distributed among FI such that the amount of deposits that each FI receives at the end of the goods market is identical across all FI within a country. ${ }^{11}$

Settlement and Foreign Exchange Market. $\quad V_{S}\left(m^{1}, m^{2}, \ell^{1}, \ell^{2}, d^{1}, d^{2}, z^{1}, z^{2}, d_{s}^{1}\right)$ denotes the value of a country 1 FI when entering the settlement and foreign exchange market with $d_{s}^{1}$ units of bank deposits from sellers. The remaining variables are identical to the benchmark model. The value function at the beginning of the settlement market is

$$
V_{S}^{1}\left(m^{1}, m^{2}, \ell^{1}, \ell^{2}, d^{1}, d^{2}, z^{1}, z^{2}, d_{s}^{1}\right)=\max _{h, x, m^{1}} x-h+V_{M}\left(m^{1}\right)
$$

s.t. $x+\phi^{1} m^{\prime 1}+\phi^{1} \frac{d_{s}^{1}}{\rho_{s}^{1}}=h+\phi^{1} m^{1}+\phi^{2} m^{2}+\phi^{1} \frac{d^{1}}{\rho_{d}^{1}}+\phi^{2} \frac{d^{2}}{\rho_{d}^{2}}-\phi^{1} \frac{\ell^{1}}{\rho_{\ell}^{1}}-\phi^{2} \frac{\ell^{2}}{\rho_{\ell}^{2}}-\phi^{1} \frac{z^{1}}{\rho_{m}^{1}}-\phi^{2} \frac{z^{2}}{\rho_{m}^{2}}+\phi^{1} \tau M^{1}$, where $\rho_{s}^{1}=1 /\left(1+i_{s}^{1}\right)$ and $i_{s}^{1}$ is the interest rate sellers receive on their deposits. Rearranging the budget constraint for $x-h$ and plugging the expression into the value function, I obtain the first-order condition

$$
V_{M}^{m^{1^{\prime}}} \leq \phi^{1}\left(=\text { if } m^{\prime 1}>0\right) .
$$

As in the benchmark model, Equation (32) implies that all FI enter the money market with identical currency 1 holdings, yielding a degenerate distribution of currency 1 holdings. The envelope conditions satisfy

$$
V_{S}^{m^{1}}=\phi^{1}, V_{S}^{m^{2}}=\phi^{2}, V_{S}^{\ell^{j}}=-\frac{\phi^{j}}{\rho_{\ell}^{j}}, V_{S}^{d^{j}}=\frac{\phi^{j}}{\rho_{d}^{j}}, V_{S}^{z^{j}}=-\frac{\phi^{j}}{\rho_{m}^{j}}, V_{S}^{d_{s}^{1}}=-\frac{\phi^{1}}{\rho_{s}^{1}},
$$

for $j=1,2$.

Money and Goods Market. Sellers choose how many goods to produce and sell for currency 1 and currency 2. Sellers deposit their earnings at bank accounts held with FI at the end of the goods market and receive an interest rate $i_{s}^{j}$ for $j=1,2$ on their deposits. It is straightforward to show that sellers are indifferent as to which currency to accept and how much to produce if

$$
\beta \phi_{+1}^{1} \frac{p^{11}}{\rho_{s}^{1}}=\beta \phi_{+1}^{1} \frac{p^{12}}{\rho_{s}^{2}}=1
$$

\footnotetext{
${ }^{11}$ As mentioned above, this extension follows Berentsen and Ruprecht (2020).
} 
holds. The relevant interest rate is now the interest rate sellers receive on their deposits held with FI.

The maximization problem of a $\varepsilon$-FI is identical to the benchmark model and is therefore omitted for brevity.

Lemma 5. There exist two critical values $\varepsilon_{d^{\prime}}^{1}, \varepsilon_{M^{\prime}}^{1}$ for country 1 FI. If $\rho_{m}^{1} / \rho_{s}^{1} \geq \rho_{m}^{2} / \rho_{s}^{2}$, then a FI with $0 \leq \varepsilon \leq \varepsilon_{d^{\prime}}^{1}$ lends currency 1 in money market 1 and a FI with $\varepsilon>\varepsilon_{d^{\prime}}^{1}$ borrows currency 1 in money market 1 . If $\rho_{m}^{1} / \rho_{s}^{1}<\rho_{m}^{2} / \rho_{s}^{2}$, then a FI with $0 \leq \varepsilon \leq \varepsilon_{d^{\prime}}^{1}$ lends currency 1 in money market 1 , a FI with $\varepsilon_{d^{\prime}}^{1}<\varepsilon \leq \varepsilon_{M^{\prime}}^{1}$ borrows currency 1 in money market 1 and a FI with $\varepsilon>\varepsilon_{M^{\prime}}^{1}$ borrows currency 2 in money market 2 . The critical values $\varepsilon_{d^{\prime}}^{1}$ and $\varepsilon_{M^{\prime}}^{1}$ satisfy

$$
\begin{aligned}
\varepsilon_{d^{\prime}}^{1} & =\frac{m^{1} \frac{\rho_{s}^{1}}{p^{11}}}{\rho_{m}^{1}} \\
\varepsilon_{M^{\prime}}^{1} & =\frac{\beta \phi_{+1}^{2} \frac{k_{b}^{2}}{\rho_{m}^{2}}}{\log \left(\frac{\rho_{m}^{2}}{\rho_{s}^{2}}\right)-\log \left(\frac{\rho_{m}^{1}}{\rho_{s}^{1}}\right)} .
\end{aligned}
$$

The quantity borrowed and lent by a FI in the money market with liquidity shock $\varepsilon$ and the quantity of goods consumed by the FI satisfy:

$$
q_{\varepsilon}=\varepsilon \frac{\rho_{m}^{1}}{\rho_{s}^{1}}, z_{\varepsilon}^{1}=p^{11} \frac{\rho_{m}^{1}}{\rho_{s}^{1}}\left(\varepsilon-\varepsilon_{d^{\prime}}^{1}\right), \forall \varepsilon,
$$

if $\rho_{m}^{1} / \rho_{s}^{1} \geq \rho_{m}^{2} / \rho_{s}^{2}$. The quantity borrowed and lent by a FI in the money market with liquidity shock $\varepsilon$ and the quantity of goods consumed by the FI satisfy:

$$
\begin{array}{llll}
q_{\varepsilon}=\varepsilon \frac{\rho_{m}^{1}}{\rho_{s}^{1}}, & z_{\varepsilon}^{1}=p^{11} \frac{\rho_{m}^{1}}{\rho_{s}^{1}}\left(\varepsilon-\varepsilon_{d^{\prime}}^{1}\right) & z_{\varepsilon}^{2}=0, & \text { if } 0 \leq \varepsilon \leq \varepsilon_{M^{\prime}}^{1} \\
q_{\varepsilon}=\varepsilon \frac{\rho_{m}^{2}}{\rho_{s}^{2}}, & z_{\varepsilon}^{1}=m^{1}, & z_{\varepsilon}^{2}=\frac{p^{12}}{e_{+1}} \frac{\rho_{m}^{2}}{\rho_{s}^{2}} \varepsilon, & \text { if } \varepsilon>\varepsilon_{M^{\prime}}^{1},
\end{array}
$$

if $\rho_{m}^{1} / \rho_{s}^{1}<\rho_{m}^{2} / \rho_{s}^{2}$.

The proof of Lemma 5 can be found in Appendix C.2.

Assumption 3. I assume further that the cost of accessing the foreign money market $k_{b}^{2}$ now satisfies

$$
k_{b}^{2}>\underline{k_{b^{\prime}}^{2}}=\varepsilon_{d}^{1}\left(\log \left(\frac{\rho_{m}^{2}}{\rho_{s}^{2}}\right)-\log \left(\frac{\rho_{m}^{1}}{\rho_{s}^{1}}\right)\right) \frac{\rho_{m}^{2}}{\beta \phi_{+1}^{2}},
$$

which ensures that $\varepsilon_{M^{\prime}}^{1}>\varepsilon_{d^{\prime}}^{1}$. 
Equilibrium. Again, I focus on stationary and symmetric equilibria with a strictly positive demand for currency 1 and a positive initial money stock, $M_{0}^{j}>0$ for $j=1,2$. Recall, $\gamma^{1}=M_{+1}^{1} / M^{1}$ is the gross growth rate of the money stock of currency 1 . Such equilibria meet the following requirements: (i) the decisions of sellers and FI are optimal given prices; (ii) The decisions are symmetric across sellers and symmetric across FI with the same $\varepsilon$-shock; (iii) All markets clear; (iv) All real quantities remain constant over time; (v) The law of motion for the stock of currency 1, Equation (16), holds in each period.

Denote $q_{s^{\prime}}^{j k}$ is the amount sold by sellers in country $j$ for currency $k$. For $\rho_{m}^{1} / \rho_{s}^{2}<\rho_{m}^{2} / \rho_{s}^{2}$ the goods market clearing conditions in country 1 satisfies

$$
\begin{aligned}
q_{s^{\prime}}^{11} & =\int_{0}^{\varepsilon_{M^{\prime}}^{1}}\left(\varepsilon \frac{\rho_{m}^{1}}{\rho_{s}^{1}}\right) d F(\varepsilon), \\
q_{s^{\prime}}^{12} & =\int_{\varepsilon_{M^{\prime}}^{1}}^{\infty}\left(\varepsilon \frac{\rho_{m}^{2}}{\rho_{s}^{2}}\right) d F(\varepsilon) .
\end{aligned}
$$

For $\rho_{m}^{1} / \rho_{s}^{1} \geq \rho_{m}^{2} / \rho_{s}^{2}$, the goods market clearing condition satisfies

$$
q_{s^{\prime}}^{11}=\int_{0}^{\infty}\left(\varepsilon \frac{\rho_{m}^{1}}{\rho_{s}^{1}}\right) d F(\varepsilon)
$$

As in the benchmark model, denote $\left(\rho_{m}^{1}\right)^{u}$ the money market rate in money market 1 that would result in equilibrium, if the money market rate were not affected by the standing facilities $\left(\rho_{\ell}^{1}, \rho_{d}^{1}\right)$. Recall, $n^{21} z^{21}$ denotes the constant amount that country 2 FI borrow in money market 1 .

The money market clearing conditions is

$$
\int_{0}^{\varepsilon_{d^{\prime}}^{1}} p^{11} \frac{\left(\rho_{m}^{1}\right)^{u}}{\rho_{s}^{1}}\left(\varepsilon_{d^{\prime}}^{1}-\varepsilon\right) d F(\varepsilon)+\int_{\varepsilon_{M^{\prime}}^{1}}^{\infty} m^{1} d F(\varepsilon)=\int_{\varepsilon_{d^{\prime}}^{1}}^{\varepsilon_{M^{\prime}}^{1}} p^{11} \frac{\left(\rho_{m}^{1}\right)^{u}}{\rho_{s}^{1}}\left(\varepsilon-\varepsilon_{d^{\prime}}^{1}\right) d F(\varepsilon)+n^{21} z^{21} .
$$

for $\rho_{m}^{1} / \rho_{s}^{1}<\rho_{m}^{2} / \rho_{s}^{2}$.

For $\rho_{m}^{1} / \rho_{s}^{1} \geq \rho_{m}^{2} / \rho_{s}^{2}$, the money market clearing conditions is

$$
\int_{0}^{\varepsilon_{d^{\prime}}^{1}} p^{11} \frac{\left(\rho_{m}^{1}\right)^{u}}{\rho_{s}^{1}}\left(\varepsilon_{d^{\prime}}^{1}-\varepsilon\right) d F(\varepsilon)=\int_{\varepsilon_{d^{\prime}}^{1}}^{\infty} p^{11} \frac{\left(\rho_{m}^{1}\right)^{u}}{\rho_{s}^{1}}\left(\varepsilon-\varepsilon_{d^{\prime}}^{1}\right) d F(\varepsilon)+n^{21} z^{21} .
$$


Rewriting the money market clearing condition for both cases yields

$$
\rho_{m}^{1}= \begin{cases}\rho_{d}^{1}, & \text { if } D^{1}\left(\rho_{d}^{1}\right)<S^{1}\left(\rho_{d}^{1}\right) \\ \rho_{\ell}^{1}, & \text { if } D^{1}\left(\rho_{\ell}^{1}\right)>S^{1}\left(\rho_{\ell}^{1}\right) \\ \left(\rho_{m}^{1}\right)^{u}, & \text { otherwise, }\end{cases}
$$

where $D^{1}$ denotes the demand and $S^{1}$ denotes the supply in money market 1 .

Proposition 6. If $\rho_{m}^{1} / \rho_{s}^{1}<\rho_{m}^{2} / \rho_{s}^{2}$, then a symmetric and stationary equilibrium with a positive demand for reserves is a policy $\left(\rho_{d}^{1}, \rho_{\ell}^{1}\right)$ and endogenous variables $\left(\varepsilon_{d^{\prime}}^{1}, \varepsilon_{M^{\prime}}^{1}, \rho_{m}^{1}\right)$ satisfying Equations (36), (43), and

$$
\frac{\gamma^{1} \rho_{s}^{1}}{\beta}=\int_{0}^{\varepsilon_{M^{\prime}}^{1}} \frac{\rho_{s}^{1}}{\rho_{m}^{1}} d F(\varepsilon)+\int_{\varepsilon_{M^{\prime}}^{1}}^{\infty} \frac{\rho_{s}^{2}}{\rho_{m}^{2}} d F(\varepsilon)
$$

If $\rho_{m}^{1} / \rho_{s}^{1} \geq \rho_{m}^{2} / \rho_{s}^{2}$, then a symmetric and stationary equilibrium with a positive demand for reserves is a policy $\left(\rho_{d}^{1}, \rho_{\ell}^{1}\right)$ and endogenous variables $\left(\varepsilon_{d^{\prime}}^{1}, \rho_{m}^{1}\right)$ satisfying Equations (43), and

$$
\frac{\gamma^{1} \rho_{s}^{1}}{\beta}=\int_{0}^{\infty} \frac{\rho_{s}^{1}}{\rho_{m}^{1}} d F(\varepsilon)
$$

The proof of Proposition 6 is in Appendix C.2. In a type II equilibrium, Proposition 6 determines endogenous variables $\left(\rho_{m}^{1}, \varepsilon_{d^{\prime}}^{1}, \varepsilon_{M^{\prime}}^{1}\right)$. In a type I equilibrium, Proposition 6 determines endogenous variables $\left(\rho_{m}^{1}, \varepsilon_{d^{\prime}}^{1}\right)$. The rest is determined as follows: Equation (1) determines the exchange rate $e_{+1}$ and Equation (34) determines $\phi_{+1}^{1}$ in a type I equilibrium and $\phi_{+1}^{1}$ and $p^{12}$ in a type II equilibrium. The quantity of goods produced is determined by Equation (40) in a type I equilibrium and by Equation (39) in a type II equilibrium. The quantities consumed are determined in Lemma 5. Market clearing for currency 1 in the settlement and foreign exchange market requires $\int_{0}^{\infty} m^{1} d F(\varepsilon)=m^{1}$ or $m^{1}=M^{1}$. It is further convenient to normalize $M^{1}=1$, such that Equation (35) determines the price level $1 / p^{11}$. 


\section{Appendix B}

Proof of Lemma 1. Combining Equations (7) and (8) yields

$$
\varepsilon u^{\prime}\left(q_{\varepsilon}\right)=\beta \phi_{+1}^{1} p^{11} \frac{1}{\rho_{m}^{1}} .
$$

Using Equation (6) and $u\left(q_{\varepsilon}\right)=\log \left(q_{\varepsilon}\right)$, the quantity consumed satisfies

$$
q_{\varepsilon}=\varepsilon \frac{\rho_{m}^{1}}{\rho_{d}^{1}} .
$$

Since consumption is strictly increasing and linear in $\varepsilon$, there exists a $\varepsilon_{d}^{1}$ for which a country $1 \mathrm{FI}$ is indifferent between borrowing and lending currency 1 in the money market 1. This FI has brought the exact amount of currency 1 into the money market to finance their desired quantity of the consumption good. The quantities consumed for this FI satisfies

$$
q_{\varepsilon_{d}^{1}}=\frac{m^{1}}{p^{11}}
$$

The consumption of this FI satisfies $q_{\varepsilon_{d}^{1}}=\varepsilon_{d}^{1} \frac{\rho_{m}^{1}}{\rho_{d}^{1}}=\frac{m^{1}}{p^{11}}$. Solving for the critical value $\varepsilon_{d}^{1}$ yields

$$
\varepsilon_{d}^{1}=\frac{m^{1}}{p^{11}} \frac{\rho_{d}^{1}}{\rho_{m}^{1}} .
$$

The amount borrowed or lent out by a FI, who chose to enter money market 1 can be derived from the budget constraint, $m^{1}+z_{\varepsilon}^{1}=p^{11} q_{\varepsilon}$. Plugging in the expression for consumption and rearranging yields

$$
z_{\varepsilon}^{1}=p^{11} \frac{\rho_{m}^{1}}{\rho_{d}^{1}}\left(\varepsilon-\varepsilon_{d}^{1}\right) .
$$

For FI that have chosen to borrow in money market 2, there are two options: First, the FI can spend the money holdings $m^{1}$ on consumption or second, the FI can lend out money holdings $m^{1}$ in money market 1 and finance its consumption only from borrowing in the money market 2. Denote $q_{\varepsilon}^{j k}$, the amount of goods purchased with in country $j$ with currency $k$.

First, I solve for the first option. In this case, $m^{1}=p^{11} q_{\varepsilon}^{11}$ has to hold. The quantities consumed can be derived from combining Equations (10) and (11), which yields

$$
\varepsilon u^{\prime}\left(q_{\varepsilon}\right)=\beta \phi_{+1}^{1} p^{12} \frac{1}{\rho_{m}^{2}} .
$$


Using Equation (6) and $u\left(q_{\varepsilon}\right)=\log \left(q_{\varepsilon}\right)$, the quantity consumed satisfies

$$
q_{\varepsilon}=\varepsilon \frac{\rho_{m}^{2}}{\rho_{d}^{2}} .
$$

The amount borrowed or lent can be derived from the budget constraint $p^{11} q_{\varepsilon}^{11}+$ $\frac{p^{12}}{e_{+1}} q_{\varepsilon}^{12}+k_{b}^{2}=m^{1}+z_{\varepsilon}^{2}$. As stated before $m^{1}=p^{11} q_{\varepsilon}^{11}$ and the budget constraint simplifies to $\frac{p^{12}}{e_{+1}} q_{\varepsilon}^{12}+k_{b}^{2}=z_{\varepsilon}^{2}$. Note further, $q_{\varepsilon}=\varepsilon \rho_{m}^{2} / \rho_{d}^{2}=q_{\varepsilon}^{11}+q_{\varepsilon}^{12}$. Rearranging the budget constraint yields the amount borrowed in money market 2 ,

$$
z_{\varepsilon}^{2}=\frac{p^{12}}{e_{+1}}\left(\varepsilon \frac{\rho_{m}^{2}}{\rho_{d}^{2}}-\frac{m^{1}}{p^{11}}\right)+k_{b}^{2}
$$

In the second option, the FI lends out its currency 1 holdings in money market 1 , $z_{\varepsilon}^{1}=m^{1} / p^{11}$. Thus, $\left(p^{12} / e_{+1}\right) q_{\varepsilon}^{12}+k_{b}^{2}=z_{\varepsilon}^{2}$.

From Equations (10) and (11), the quantities consumed satisfy

$$
q_{\varepsilon}=\varepsilon \frac{\rho_{m}^{2}}{\rho_{d}^{2}}
$$

The amount borrowed and lent in the two money markets satisfy

$$
z_{\varepsilon}^{1^{\prime}}=\frac{m^{1}}{p^{11}}, z_{\varepsilon}^{2^{\prime}}=\frac{p^{12}}{e_{+1}} \varepsilon \frac{\rho_{m}^{2}}{\rho_{d}^{2}}+k_{b}^{2}
$$

FI are indifferent between the two options if the value of taking the first option is equal to the value of taking the second option for a given $\varepsilon$. Thus,

$$
\varepsilon u\left(q_{\varepsilon}\right)-\beta \phi_{+1}^{2} z_{\varepsilon}^{2} / \rho_{m}=\varepsilon u\left(q_{\varepsilon}\right)-\beta \phi_{+1}^{1} z_{\varepsilon}^{1^{\prime}} / \rho_{m}^{1}-\beta \phi_{+1}^{2} z_{\varepsilon}^{2^{\prime}} / \rho_{m}^{2} .
$$

Rearranging yields

$$
\frac{\rho_{m}^{2}}{\rho_{d}^{2}}=\frac{\rho_{m}^{1}}{\rho_{d}^{1}} .
$$

Note, for $\rho_{m}^{1} / \rho_{d}^{1} \geq \rho_{m}^{2} / \rho_{d}^{2}$, the value of accessing money market 1 is always larger than the value of accessing money market 2 . Therefore, if FI choose to access money market 2 , it must be that $\rho_{m}^{1} / \rho_{d}^{1}<\rho_{m}^{2} / \rho_{d}^{2}$. Thus, for a FI that chooses to access money market 2 , it is always optimal to lend money holdings $m^{1}$ in money market 1 and finance the quantities consumed by borrowing from money market 2 . Thus $z_{\varepsilon}^{1}=m^{1}$ and $z_{\varepsilon}^{2}=\left(p^{12} / e_{+1}\right) \varepsilon\left(\rho_{m}^{2} / \rho_{d}^{2}\right)$.

Further, depending on the relative ratio of the money market rate and the deposit rate, there may exist a critical value $\varepsilon_{M}^{1}$ for which a $\varepsilon$-FI is indifferent between accessing money market 1 and money market 2 . Here, we can distinguish between two cases. First, 
if $\rho_{m}^{1} / \rho_{d}^{1}<\rho_{m}^{2} / \rho_{d}^{2}$, there exists a critical value $\varepsilon_{M}^{1}$, for which a $\varepsilon$-FI is indifferent between accessing money market 1 and money market 2 . The critical value $\varepsilon_{M}^{1}$ satisfies

$$
\begin{aligned}
& \varepsilon_{M}^{1} u\left(q_{\varepsilon_{M}^{1}}\right)+\beta V_{S}\left(m^{1}+z_{\varepsilon_{M}^{1}}^{1}-p^{11} q_{\varepsilon_{M}^{1}}^{1}, 0,0,0,0, z_{\varepsilon_{M}^{1}}^{1}, 0\right) \\
& =\varepsilon_{M}^{1} u\left(q_{\varepsilon_{M}^{1}}\right)+\beta V_{S}\left(m^{1}+z_{\varepsilon_{M}^{1}}^{1}, z_{\varepsilon_{M}^{1}}^{2}-\frac{p^{12}}{e_{+1}} q_{\varepsilon_{M}^{1}}^{12}-k_{b}^{2}, 0,0,0,0, z_{\varepsilon_{M}^{1}}^{1}, z_{\varepsilon_{M}^{1}}^{2}\right) .
\end{aligned}
$$

Using the equations for the quantities consumed and borrowed in the money market as well as $\varepsilon u\left(q_{\varepsilon}\right)=\varepsilon \log \left(q_{\varepsilon}\right)$ yields

$$
\varepsilon_{M}^{1}=\frac{\beta \phi_{+1}^{2} \frac{k_{b}^{2}}{\rho_{m}^{2}}}{\log \left(\frac{\rho_{m}^{2}}{\rho_{d}^{2}}\right)-\log \left(\frac{\rho_{m}^{1}}{\rho_{d}^{1}}\right)} .
$$

Note further, for small values of $k_{b}^{2}, \varepsilon_{d}^{1}>\varepsilon_{M}^{1}$. This implies that some FI who lend currency 1 in money market 1 would prefer to lend money in money market 2 . Since these FI only carry currency 1 , this is however not possible. Therefore for

$$
k_{b}^{2}>\varepsilon_{d}^{1}\left(\log \left(\frac{\rho_{m}^{2}}{\rho_{d}^{2}}\right)-\log \left(\frac{\rho_{m}^{1}}{\rho_{d}^{1}}\right)\right)\left(\beta \phi_{+1}^{2} / \rho_{m}^{2}\right)^{-1}=\underline{k_{b}^{2}},
$$

$\varepsilon_{M}^{1}>\varepsilon_{d}^{1}$ holds. Second, for $\rho_{m}^{1} / \rho_{d}^{1} \geq \rho_{m}^{2} / \rho_{d}^{2}, \varepsilon_{M}^{1}$ is either indeterminate or negative. Thus, for $\rho_{m}^{1} / \rho_{d}^{1} \geq \rho_{m}^{2} / \rho_{d}^{2}$, there exists no critical value $\varepsilon_{M}^{1}$.

Proof of Proposition 2. The following proof shows the derivation of Equation (22) and (23). First, the value function at the beginning of the money market for a country 1 FI satisfies

$$
\begin{gathered}
V_{M}\left(m^{1}\right)=\max _{q_{\varepsilon}, z_{\varepsilon}^{1}, z_{\varepsilon}^{2}, \ell_{\varepsilon}^{1}, \ell_{\varepsilon}^{2}, d_{\varepsilon}^{1}, d_{\varepsilon}^{2}} \int_{0}^{\infty} \varepsilon u\left(q_{\varepsilon}\right)+\beta V_{S}\left(m^{1}, m^{2}, \ell_{\varepsilon}^{1}, \ell_{\varepsilon}^{2}, d_{\varepsilon}^{1}, d_{\varepsilon}^{2}, z_{\varepsilon}^{1}, z_{\varepsilon}^{2}\right) d F(\varepsilon) . \\
\text { s.t. } m^{1}+z_{\varepsilon}^{1}+\ell_{\varepsilon}^{1}-p^{11} q_{\varepsilon}^{11}-d_{\varepsilon}^{1} \geq 0, \quad z_{\varepsilon}^{2}+\ell_{\varepsilon}^{2}-\frac{p^{12}}{e_{+1}} q_{\varepsilon}^{12}-k_{b}^{2}-d_{\varepsilon}^{2} \geq 0 .
\end{gathered}
$$

Taking the derivative with respect to money holdings $m^{1}$ yields $V_{M}^{m^{1}}\left(m^{1}\right)=\int_{0}^{\infty} \beta V_{S}^{m}\left(m^{1}+z_{\varepsilon}^{1}+\ell_{\varepsilon}^{1}-p^{11} q_{\varepsilon}^{11}-d_{\varepsilon}^{1}, z_{\varepsilon}^{2}+\ell_{\varepsilon}^{2}-\frac{p^{12}}{e_{+1}} q_{\varepsilon}-k_{b}^{2}-d^{2}, \ell_{\varepsilon}^{1}, \ell_{\varepsilon}^{2}, d_{\varepsilon}^{1}, d_{\varepsilon}^{2}, z_{\varepsilon}^{1}, z_{\varepsilon}^{2} \mid \varepsilon\right)+\beta \phi_{+1}^{1} \lambda_{\varepsilon}^{11} d F(\varepsilon)$.

Using Equation (5) to replace $V_{S}^{m}$ and Equation (7) to replace $\beta \phi_{+1}^{1} \lambda_{\varepsilon}^{11}$, I obtain

$$
V_{M}^{m^{1}}\left(m^{1}\right)=\int_{0}^{\infty} \frac{\varepsilon u^{\prime}\left(q_{\varepsilon}\right)}{p^{11}} d F(\varepsilon)
$$


Next, using Equation (6) to replace $p^{11}$ yields

$$
V_{M}^{m^{1}}\left(m^{1}\right)=\frac{\beta \phi_{+1}^{1}}{\rho_{d}^{1}} \int_{0}^{\infty} \varepsilon u^{\prime}\left(q_{\varepsilon}\right) d F(\varepsilon) .
$$

Using $\frac{\phi^{1}}{\phi_{+1}^{1}}=\gamma^{1}$ and Lemma 1, I obtain Equation (22), which is reproduced here:

$$
\frac{\gamma^{1} \rho_{d}^{1}}{\beta}=\int_{0}^{\varepsilon_{M}^{1}} \frac{\rho_{d}^{1}}{\rho_{m}^{1}} d F(\varepsilon)+\int_{\varepsilon_{M}^{1}}^{\infty} \frac{\rho_{d}^{2}}{\rho_{m}^{2}} d F(\varepsilon),
$$

for $\rho_{m}^{1} / \rho_{d}^{1}<\rho_{m}^{2} / \rho_{d}^{2}$. And for $\rho_{m}^{1} / \rho_{d}^{1}>\rho_{m}^{2} / \rho_{d}^{2}$, I obtain Equation (23), which is reproduced here:

$$
\frac{\gamma^{1} \rho_{d}^{1}}{\beta}=\int_{0}^{\infty} \frac{\rho_{d}^{1}}{\rho_{m}^{1}} d F(\varepsilon)
$$

Proof of Proposition 3. Setting $\rho_{d}^{1}=\frac{\beta}{\gamma^{1}}$ and plugging this into Equation (22) yields

$$
1=\int_{0}^{\varepsilon_{M}^{1}} \frac{\rho_{d}^{1}}{\rho_{m}^{1}} d F(\varepsilon)+\int_{\varepsilon_{M}^{1}}^{\infty} \frac{\rho_{d}^{2}}{\rho_{m}^{2}} d F(\varepsilon) .
$$

This equation holds if and only if $\varepsilon_{d}^{1} \rightarrow \infty$ and $\rho_{d}^{1}=\rho_{m}^{1}$, since $\frac{\rho_{d}^{1}}{\rho_{m}^{1}} \geq 1$ and $\frac{\rho_{d}^{2}}{\rho_{m}^{2}} \geq 1$. Thus, the right-hand side cannot be smaller than one. Then, if $\varepsilon_{d}^{1} \rightarrow \infty, \varepsilon_{M}^{1} \rightarrow \infty$ must hold and the equation approaches

$$
1=\int_{0}^{\infty} \frac{\beta}{\gamma^{1} \rho_{m}^{1}} d F(\varepsilon)+\int_{\infty}^{\infty} \frac{\rho_{d}^{2}}{\rho_{m}^{2}} d F(\varepsilon)
$$

This means that $\rho_{m}^{1} \rightarrow \frac{\beta}{\gamma^{1}}$ as $\varepsilon_{d}^{1} \rightarrow \infty$. Similarly, plugging in $\rho_{d}^{1}=\frac{\beta}{\gamma^{1}}$ in Equation (23) yields

$$
1=\int_{0}^{\infty} \frac{\rho_{d}^{1}}{\rho_{m}^{1}} d F(\varepsilon)
$$

Again, this equations holds if and only if $\rho_{m}^{1}=\rho_{d}^{1}$.

Proof of Proposition 4. Using Equation (23) and solving for $\rho_{m}^{1}$ yields

$$
\rho_{m}^{1}=\frac{\beta}{\gamma^{1}} \int_{0}^{\infty} d F(\varepsilon)
$$

Plugging this into Equation (20), using Equation (6) and $\int_{0}^{\infty} d F(\varepsilon)=1$ yields 


$$
\phi^{1} m^{1}=\int_{0}^{\infty} \varepsilon d F(\varepsilon)+n^{21} z^{21}
$$

Proof of Lemma 5. Using Equations (7) and (8) yields

$$
\varepsilon u^{\prime}\left(q_{\varepsilon}\right)=\beta \phi_{+1}^{1} p^{11} \frac{1}{\rho_{m}^{1}} .
$$

Using Equation (34) and $u\left(q_{\varepsilon}\right)=\log \left(q_{\varepsilon}\right)$, the amount consumed satisfies

$$
q_{\varepsilon}=\varepsilon \frac{\rho_{m}^{1}}{\rho_{s}^{1}}
$$

Denote $\varepsilon_{d^{\prime}}^{1}$ the critical value for which a FI is indifferent between borrowing and lending in money market 1 . The quantities consumed for this FI satisfies therefore

$$
q_{\varepsilon_{d^{\prime}}^{1}}=\frac{m^{1}}{p^{11}}
$$

In addition, the consumption of this FI satisfies $q_{\varepsilon_{d^{\prime}}^{1}}=\varepsilon_{d^{\prime}}^{1} \frac{\rho_{m}^{1}}{\rho_{s}^{1}}=\frac{m^{1}}{p^{11}}$. Solving for the critical value $\varepsilon_{d^{\prime}}^{1}$ yields

$$
\varepsilon_{d^{\prime}}^{1}=\frac{m^{1}}{p^{11}} \frac{\rho_{s}^{1}}{\rho_{m}^{1}} .
$$

Using the budget constraint $m^{1}+z_{\varepsilon}^{1}=p^{11} q_{\varepsilon}$, I solve for the amount borrowed or lent. Rearranging yields

$$
z_{\varepsilon}^{1}=p^{11} \frac{\rho_{m}^{1}}{\rho_{s}^{1}}\left(\varepsilon-\varepsilon_{d^{\prime}}^{1}\right)
$$

As shown above, FI that choose to access money market 2 prefer to lend their currency 1 holdings in money market 1 and borrow in money market 2 . Thus, $z_{\varepsilon}^{1}=m^{1} / p^{11}$ and $\left(p^{12} / e_{+1}\right) q_{\varepsilon}^{12}+k_{b}^{2}=z_{\varepsilon}^{2}$.

From Equations (10), (11) and (34), the quantities consumed satisfy

$$
q_{\varepsilon}=\varepsilon \frac{\rho_{m}^{2}}{\rho_{s}^{2}} .
$$

Thus, the amount borrowed and lent in the two money markets satisfy

$$
z_{\varepsilon}^{1}=\frac{m^{1}}{p^{11}}, z_{\varepsilon}^{2}=\frac{p^{12}}{e_{+1}} \varepsilon \frac{\rho_{m}^{2}}{\rho_{s}^{2}}+k_{b}^{2} .
$$


Next, I derive the critical value $\varepsilon_{M^{\prime}}^{1}$ for which a FI is indifferent between accessing money market 1 and money market 2 . The critical value $\varepsilon_{M^{\prime}}^{1}$ satisfies

$$
\begin{aligned}
& \varepsilon_{M^{\prime}}^{1} u\left(q_{\varepsilon_{M^{\prime}}^{1}}\right)+\beta V_{S}\left(m^{1}+z_{\varepsilon_{M^{\prime}}^{1}}^{1}-p^{11} q_{\varepsilon_{M^{\prime}}^{1}}^{11}, 0,0,0,0, z_{\varepsilon_{M^{\prime}}^{1}}^{1}, 0\right) \\
& =\varepsilon_{M^{\prime}}^{1} u\left(q_{\varepsilon_{M^{\prime}}^{1}}\right)+\beta V_{S}\left(m^{1}+z_{\varepsilon_{M^{\prime}}^{1}}^{1}, z_{\varepsilon_{M^{\prime}}^{1}}^{2}-\frac{p^{12}}{e_{+1}} q_{\varepsilon_{M^{\prime}}^{1}}^{12}-k_{b}^{2}, 0,0,0,0, z_{\varepsilon_{M^{\prime}}^{1}}^{1}, z_{\varepsilon_{M^{\prime}}^{1}}^{2}\right) .
\end{aligned}
$$

Using the equations for consumption and the amount borrowed or lent yields

$$
\varepsilon_{M^{\prime}}^{1}=\frac{\beta \phi_{+1}^{2} \frac{k_{b}^{2}}{\rho_{m}^{2}}}{\log \left(\frac{\rho_{m}^{2}}{\rho_{s}^{2}}\right)-\log \left(\frac{\rho_{m}^{1}}{\rho_{s}^{1}}\right)} .
$$

Moreover, for

$$
k_{b}^{2}>\varepsilon_{d^{\prime}}^{1}\left(\log \left(\frac{\rho_{m}^{2}}{\rho_{s}^{2}}\right)-\log \left(\frac{\rho_{m}^{1}}{\rho_{s}^{1}}\right)\right)\left(\beta \phi_{+1}^{2} / \rho_{m}^{2}\right)^{-1}=\underline{k_{b^{\prime}}^{2}}
$$

$\varepsilon_{M^{\prime}}^{1}>\varepsilon_{d^{\prime}}^{1}$ holds.

Proof of Proposition 6. Here, I derive Equations (45) and (44). Taking the derivative of the value function at the beginning of the money market for country 1 FI with respect to $m^{1}$ yields

$V_{M}^{m^{1}}\left(m^{1}\right)=\int_{0}^{\infty} \beta V_{S}^{m}\left(m^{1}+z_{\varepsilon}^{1}+\ell_{\varepsilon}^{1}-p^{11} q_{\varepsilon}^{11}-d_{\varepsilon}^{1}, z_{\varepsilon}^{2}+\ell_{\varepsilon}^{2}-\frac{p^{12}}{e_{+1}} q_{\varepsilon}-k_{b}^{2}-d^{2}, \ell_{\varepsilon}^{1}, \ell_{\varepsilon}^{2}, d_{\varepsilon}^{1}, d_{\varepsilon}^{2}, z_{\varepsilon}^{1}, z_{\varepsilon}^{2}, d_{s}^{1} \mid \varepsilon\right)+\beta \phi_{+1}^{1} \lambda_{\varepsilon}^{11} d F(\varepsilon)$.

Using Equation (5) to replace $V_{S}^{m}$ and Equation (7) to replace $\beta \phi_{+1}^{1} \lambda_{\varepsilon}^{11}$, I obtain

$$
V_{M}^{m^{1}}\left(m^{1}\right)=\int_{0}^{\infty} \frac{\varepsilon u^{\prime}\left(q_{\varepsilon}\right)}{p^{11}} d F(\varepsilon) .
$$

Next, using Equation (34) to replace $p^{11}$ yields

$$
V_{M}^{m^{1}}\left(m^{1}\right)=\frac{\beta \phi_{+1}^{1}}{\rho_{s}^{1}} \int_{0}^{\infty} \varepsilon u^{\prime}\left(q_{\varepsilon}\right) d F(\varepsilon) .
$$

Replacing $\frac{\phi^{1}}{\phi_{+1}^{1}}=\gamma^{1}$ and using Lemma 5 yields

$$
\frac{\gamma^{1} \rho_{s}^{1}}{\beta}=\int_{0}^{\varepsilon_{M^{\prime}}^{1}} \frac{\rho_{s}^{1}}{\rho_{m}^{1}} d F(\varepsilon)+\int_{\varepsilon_{M^{\prime}}^{1}}^{\infty} \frac{\rho_{s}^{2}}{\rho_{m}^{2}} d F(\varepsilon),
$$

for $\rho_{m}^{1} / \rho_{s}^{1}<\rho_{m}^{2} / \rho_{s}^{2}$, which is Equation (44). For $\rho_{m}^{1} / \rho_{s}^{1} \geq \rho_{m}^{2} / \rho_{s}^{2}$ and using Lemma 5, I 
obtain

$$
\frac{\gamma^{1} \rho_{s}^{1}}{\beta}=\int_{0}^{\infty} \frac{\rho_{s}^{1}}{\rho_{m}^{1}} d F(\varepsilon),
$$

which is Equation (45). 


\section{References}

Manuel Amador, Javier Bianchi, Luigi Bocola, and Fabrizio Perri. Exchange rate policies at the zero lower bound. NBER Working Papers No. 23266, 2017.

Christoph Basten and Mike Mariathasan. How banks respond to negative interest rates: Evidence from the Swiss exemption threshold. CESifo Working Papers No. 6901, 2018.

Morten Bech and Cyril Monnet. A search-based model of the interbank money market and monetary policy implementation. Journal of Economic Theory, 164:32-67, 2016.

Morten L. Bech and Aytek Malkhozov. How have central banks implemented negative policy rates? BIS Quarterly Review March, pages 31-44, 2016.

Aleksander Berentsen and Cyril Monnet. Monetary policy in a channel system. Journal of Monetary Economics, 55(6):1067-1080, 2008.

Aleksander Berentsen and Romina Ruprecht. On the negatives of negative interest rates and the positives of exemption thresholds. mimeo, 2020.

Aleksander Berentsen, Alessandro Marchesiani, and Christopher J. Waller. Floor systems for implementing monetary policy: Some unpleasant fiscal arithmetic. Review of Economics Dynamics, 17(3):523-542, 2014.

Aleksander Berentsen, Sébastien Kraenzlin, and Benjamin Müller. Exit strategies for monetary policy. Journal of Monetary Economics, 99:20-40, 2018.

Falk Bräuning and Botao Wu. ECB monetary policy transmission during normal and negative interest rate periods. Available at SSRN: https://ssrn.com/abstract=2940553 or http://dx.doi.org/10.2139/ssrn.2940553, 2017.

Gabriele Camera, Ben Craig, and Christopher J. Waller. Currency competition in a fundamental model of money. Journal of International Economics, 64(2):521-544, 2004.

Giovanni Dell'Ariccia, Vikram Haksar, Tommaso Mancini-Griffoli, K. Eckhold, S. Gray, F. Han, G.H. Hong, E. Lundback, H. Oura, H. Poirson, et al. Negative interest rate policies - Initial experiences and assessments. IMF Policy Papers, 2017.

Selva Demiralp, Jens Eisenschmidt, and Thomas Vlassopoulos. Negative interest rates, excess liquidity and retail deposits: Banks' reaction to unconventional monetary policy in the Euro area. ECB Working Paper Series No 2283, 2019.

Feng Dong and Yi Wen. Optimal monetary policy under negative interest rate. Federal Reserve Bank of St. Louis Working Papers No. 2017-19, 2017. 
Gauti B. Eggertsson, Ragnar E. Juelsrud, Lawrence H. Summers, and Ella Getz Wold. Negative nominal interest rates and the bank lending channel. NBER Working Papers No. 25416, 2019.

Martin Eichenbaum and Charles L. Evans. Some empirical evidence on the effects of shocks to monetary policy on exchange rates. The Quarterly Journal of Economics, 110 (4):975-1009, 1995.

Jens Eisenschmidt and Frank Smets. Negative interest rates: Lessons from the Euro area. Central Banking, Analysis, and Economic Policies Book Series, in: Álvaro Aguirre 8$\}$ Markus Brunnermeier $\&$ Diego Saravia (ed.), Monetary Policy and Financial Stability: Transmission Mechanisms and Policy Implications Edition 1, 26(2):013-042, 2019.

European Central Bank. Euro money market study 2014. 2015.

Pedro Gomis-Porqueras, Timothy Kam, and Christopher Waller. Nominal exchange rate determinacy under the threat of currency counterfeiting. American Economic Journal: Macroeconomics, 9(2):256-273, 2017.

Pere Gomis-Porqueras, Timothy Kam, and Junsang Lee. Money, capital and exchange rate fluctuations. International Economic Review, 54(1):329-353, 2013.

Allaudeen Hameed and Andrew K. Rose. Exchange rate behaviour with negative interest rates: Some early negative observations. Pacific Economic Review, 23(1):27-42, 2018.

Florian Heider, Farzad Saidi, and Glenn Schepens. Life below zero: Bank lending under negative policy rates. The Review of Financial Studies, 32(10):3728-3761, 2019.

Daniel Heller and Yvan Lengwiler. Payment obligations, reserve requirements, and the demand for central bank balances. Journal of Monetary Economics, 50(2):419-432, 2003.

Harriet Jackson. The international experience with negative policy rates. Bank of Canada Staff Discussion Papers No. 2015-13, 2015.

Andreas Jobst and Huidan Lin. Negative interest rate policy (NIRP): Implications for monetary transmission and bank profitability in the Euro area. IMF Working Papers $W P / 16 / 172,2016$.

John Kareken and Neil Wallace. On the indeterminacy of equilibrium exchange rates. The Quarterly Journal of Economics, 96(2):207-222, 1981.

Guillaume A. Khayat. The impact of setting negative policy rates on banking flows and exchange rates. Economic Modelling, 68:1-10, 2018. 
Ricardo Lagos and Randall Wright. A unified framework for monetary theory and policy analysis. Journal of Political Economy, 113(3):463-484, 2005.

Ding Liu. Search models of money: Recent advances. Available at SSRN: https://ssrn.com/abstract=2792533 or http://dx.doi.org/10.2139/ssrn.2792533, 2016.

Robert E. Lucas. Interest rates and currency prices in a two-country world. Journal of Monetary Economics, 10(3):335-359, 1982.

Loriano Mancini, Angelo Ranaldo, and Jan Wrampelmeyer. The Euro interbank repo market. The Review of Financial Studies, 29(7):1747-1779, 2016.

Frederic S. Mishkin. "Symposium on the monetary transmission mechanism. The Journal of Economic Perspectives, 9(4):3-10, 1995.

Ed Nosal and Guillaume Rocheteau. Money, payments, and liquidity. MIT press, 2011.

Maurice Obstfeld and Kenneth Rogoff. Exchange rate dynamics redux. Journal of Political Economy, 103(3):624-660, 1995.

William Poole. Commercial bank reserve management in a stochastic model: Implications for monetary policy. The Journal of Finance, 23(5):769-791, 1968.

Davide Porcellacchia. Optimal negative interest on reserves. mimeo, 2018.

Matthew Rognlie. What lower bound? Monetary policy with negative interest rates. Unpublished Manuscript, 2016.

Tan Schelling and Pascal Towbin. Negative interest rates, deposit funding and bank lending. mimeo, 2018.

John B. Taylor. The role of the exchange rate in monetary-policy rules. American Economic Review, 91(2):263-267, 2001.

Rima Turk. Negative interest rates: How big a challenge for large Danish and Swedish banks? IMF Working Papers WP/16/198, 2016.

William Whitesell. Interest rate corridors and reserves. Journal of Monetary Economics, 53(6):1177-1195, 2006.

Michael Woodford. Monetary policy in a world without money. International Finance, 3 (2):229-260, 2000.

Pinar Yeşin. Capital flow waves to and from Switzerland before and after the financial crisis. Swiss Journal of Economics and Statistics, 151(1):27-75, 2015.

Cathy Zhang. An information-based theory of international currency. Journal of International Economics, 93(2):286-301, 2014. 